\title{
Cultivos trashumantes, políticas inoperantes. Un balance de la actividad cocalera en Colombia, 1998- $2017^{\star}$
}

\author{
Transhumant crops, not operating policies \\ A balance on coca-growing activity in Colombia, 1998-2017
}

\author{
Óscar Alfredo Alfonso-Roa ${ }^{1}$ \\ Docente Investigador de la Universidad Externado de Colombia \\ Bogotá, Colombia \\ oscar.alfonso@uexternado.edu.co \\ https://orcid.org/0000-0003-0781-0658 \\ Jairo Alejandro Granados-Zambrano² \\ Investigador de la Universidad Externado de Colombia \\ Bogotá, Colombia \\ jairoa.granados@uexternado.edu.co \\ https://orcid.org/0000-0002-6430-2636 \\ Laura Sofía Téllez-Barbosa ${ }^{3}$ \\ Estudiante de la Universidad Externado de Colombia \\ Bogotá, Colombia \\ laura.tellezol@est.uexternado.edu.co \\ https://orcid.org/0000-0002-3638-6414
}

Recibido: $12-10-18$

Aprobado: $27-08-19$

\footnotetext{
* Resultado del proyecto de investigación Cultivos de uso ilícito y desarrollo regional, financiado por la Universidad Externado de Colombia.

1 Doctor en Planeamiento Urbano y Regional.

2 Economista.

3 Estudiante de Economía.
} 


\section{Resumen}

Después de 20 años de programas orientados a la erradicación definitiva de los cultivos del arbusto de coca, la actividad cocalera no cesa. El objetivo de este trabajo es argumentar que una de las razones es la trashumancia de los cultivos que, ceteris paribus la presencia de grupos armados irregulares, es una estrategia de sus promotores comerciales: los narcotraficantes. A través de medidas de autocorrelación espacial se busca demostrar la existencia de tal fenómeno, para concluir en la necesidad de políticas alternativas que eviten la proliferación de la violencia y el daño a la salud y al ambiente.

Palabras clave: política sobre drogas; lucha contra la toxicomanía; estupefaciente.

\section{Abstract}

After 20 years of programs aimed at the definitive eradication of coca bush crops, coca activity does not cease. The objective of this investigation is to argue that one of the reasons for transhumance of crops that, ceteris paribus the presence of irregular armed groups, is a strategy of its commercial promoters: drug traffickers. Through measures of spatial autocorrelation it seeks to demonstrate the existence of such a phenomenon, concluding on the need for alternative policies to prevent the proliferation of violence and harm to health and the environment..

Keywords: Drug policy; Fight Against Drug Addiction; Narcotic.

¿Cómo citar este artículo? / How to quote this article?

Alfonso-Roa, O. A., Granados-Zambrano, J. A. y Téllez-Barbosa, L. S. (2020). Cultivos trashumantes, políticas inoperantes. Un balance de la actividad cocalera en Colombia, 1998-2017. Sociedad y economía, (39), 6-33. https://doi.org/10.25100/sye.voi39.8560 


\section{Introducción}

La intensa actividad cocalera en Colombia, durante las tres últimas décadas, ha situado al país como el epicentro mundial del tráfico de cocaína.

Del lado de la demanda, el volumen de consumidores consuetudinarios y eventuales se incrementa, como también su disponibilidad a pagar por el alcaloide, cuyos altibajos se atribuyen -en algunos trabajos académicos- a la prohibición y a programas de salud pública inadecuados en las sociedades consumidoras para prevenir tal expansión.

El objetivo principal de este trabajo es analizar la inoperancia de las políticas convencionales orientadas a la erradicación de los cultivos del arbusto de coca. Tal inoperancia debida a la trashumancia de los cultivos, que es una estrategia promovida por los narcotraficantes.

La autocorrelación espacial sugiere la existencia de conglomerados de municipios con crecimientos elevados de actividad cocalera, que son coetáneos a conglomerados de municipios con decrecimientos sustanciales. Se emplea el Índice de Moran para verificar tal comportamiento al finalizar las últimas cinco administraciones presidenciales de Colombia.

Los informes de monitoreo de la Oficina de las Naciones Unidas contra la Droga y el Delito -UNODC- son el antecedente más próximo a este trabajo, pero se diferencia en que en ellos se busca identificar la densidad y la continuidad de los cultivos, más no los conglomerados espaciales. Se comienza presentando un contexto marcado por los principales rasgos del mercado mundial del alcaloide, para luego abordar el análisis de las razones por las que Colombia continúa siendo el epicentro del tráfico de cocaína.

Se hará un énfasis especial sobre las consecuencias humanas, ambientales y políticas de la erradicación forzada y, en particular, de la aspersión aérea con glifosato. En el acápite final se realiza el análisis geoespacial de la trashumancia y se proponen unas reflexiones finales y líneas ulteriores de investigación.

\section{La expansión del mercado mundial de cocaína}

Hacia 1998 se estimó que el número de consumidores de cocaína en el mundo cocainómanos o usuarios eventuales- era de 14 millones (UNODC, 2016, p. xiv), y ascendió a 17 millones en el 2016 (ODC, 2017, p. 19), lapso en el que hubo picos muy elevados, como en 2014, cuando el número de consumidores llegó a los 18,8 millones. Dombois (1989, p. 117-133) analizó la división del mercado mundial entre países productores y distribuidores latinoamericanos, y países industrializados consumidores. En los países primermundistas sigue creciendo el número de consumidores consuetudinarios $\mathrm{y}$ ocasionales (UNODC, 2017b, p. 13-19) y, de forma simultánea, los países productores y distribuidores se han transformado inevitablemente en países consumidores (UNODC, 2014, p. 82). Por su parte, un kilogramo de clorhidrato que se cotizaba en el territorio colombiano a US\$1.732 en 2014 (UNODC, 2016, p. 11), se elevó en 2017 a US\$2.512.

El mercado mundial de cocaína no deja de expandirse, y a ello contribuyen otros fenómenos tales como:

a. La hoja de coca no se produce hoy como se hacía 35 años atrás, cuando se tiene noticia del surgimiento de los carteles de la droga en el país. Las variedades del arbusto de coca permiten, en la actualidad, entre 3,9 y 5,3 cosechas por año dependiendo de la zona (UNODC, 2019, p. 51). Además de los "cristalizaderos", el ácido de coca se sintetiza también en laboratorios farmacéuticos e, inclusive, en laboratorios artesanales caseros (UNODC, 2017a, p. 13-15);

b. Al haber alcanzado la etapa de estandarización dentro del ciclo internacional del producto, la cocaína se distribuye en más de una presentación: en polvo, cigarrillo chino, clorhidrato para inyectar, pasta de coca o basuco, crack o cocaína en base y cocaína rosada (Corbin, s. f.), entre las más conocidas; además, la oferta de psicoactivos se ha diversificado, especialmente de cannabinoides y cathinones sintéticos (UNODC, 2017c, p. 27-31); y, 
c. Los acuerdos globales siguen plagados de imprecisiones científicas (Thoumi, 2017a, p. 138; Thoumi, 2017b, p. 19-21), imponiéndose la continuidad del énfasis en el control de la oferta a través de políticas de erradicación forzada y aspersión aérea con herbicidas tóxicos (UNODC, 2014, p. 75) y, en menor medida, de la incautación de precursores químicos y de otros insumos (CAN, 2013, p. 44-57).

La Policía Antinarcóticos y la DEA conocen estos argumentos a fondo como, por ejemplo, que el clorhidrato es más costoso que la pasta en Colombia, pero que el margen de ganancia de los narcotraficantes que coordinan la distribución hacia los mercados del primer mundo son semejantes. En tal contexto, los discursos sobre la inoperancia de la prohibición y penalización y, de manera consecuente, de la legalización, continúan aflorando de manera reiterada desde voces muy calificadas en los ámbitos académicos (Nadelman, 1988, p. 27-39; Boyd, 2002; LSE, 2014), sin que tengan mayor resonancia en las esferas políticas de decisión. Simultáneamente, las áreas sembradas con el arbusto de coca aumentan, como es de esperarse ante tal estado de cosas.

\section{Colombia como epicentro del tráfico de cocaína y su rol en las convenciones mundiales anti-drogas}

Para Gaviria y Mejía (2011, p. 4) las razones de la primacía colombiana en el mercado mundial de cocaína no están esclarecidas. Sin embargo, sugieren que puede deberse a un accidente histórico suscitado por la ventaja competitiva, generada por los narcotraficantes colombianos, asociada al aprendizaje y la especialización alcanzada más rápidamente que otros competidores.

Caballero (2018a; 2018b) denuncia de manera reiterada la ineficacia deliberada del Departamento de Estado de los Estados Unidos en su accionar contra el narcotráfico. Ineficacia atribuida en especial a la doble moral con que actúa la DEA, pues tan solo intercepta el $1 \%$ de las drogas ilícitas que llegan a los Estados Unidos desde el extranjero y, en cambio, utiliza la estrategia de "entrampamiento" para vincular como responsables del tráfico internacional a personas vinculadas a la política, que son incómodas para las prácticas imperialistas. Es un "arma diplomática de agresión", cuyas prácticas enrarecen las acciones gubernamentales de los países productores en contra de la expansión de los cultivos.

Thoumi (2014, p. 286-289), aborda el fenómeno desde sus causas internas y, con especial énfasis, en la rentabilidad de violar las leyes en Colombia, fenómeno que distingue al país de otros con similar potencial productor del arbusto de coca.

Duncan (2014, p. 24) desarrolla el argumento de que los narcotraficantes colombianos buscan constituirse en el poder político dominante de las zonas periféricas, alterando el orden social y las instituciones que regulan las interacciones entre miembros de las sociedades sometidas a sus reglas.

Estas ideas aportan elementos de análisis relevantes al momento de buscar una explicación robusta del fenómeno. A continuación, se presentan algunos de sus rasgos ancestrales y de las políticas para combatir su expansión.

\subsection{De los cultivos ancestrales a la expansión del comercio mundial}

La visión ancestral del origen del arbusto de coca se ha construido a partir de la memoria. Tal visión se transmite de generación en generación por los maestros espirituales de los pueblos, que emplean la hoja en sus ritos. Por otro lado, hay una visión científica que se ocupa de las condiciones del ecosistema para el desarrollo de las especies.

Al inicio de la siembra, cuando el número de ramas se limita a tres y cuatro por mata, la tradición indica que se debe desprender una de las ramas y colocarla encima de un tronco en medio del cocal. La creencia ancestral sugiere que la rama que se desprende permitirá que 
las demás broten, operando como un llamado que incita a las otras ramas a salir de la mata, como un "grito" que las invita a hacer parte de la casa. Cuando Urbina-Rangel (2011, p. 200-203) le pregunta a un anciano en el Amazonas por el origen de la coca, la respuesta es que al inicio de todo los hombres solo tenían en su poder hachas de piedra y candela de piedra, instrumentos que había ganado su padre Kaï $\mathrm{Mo}^{4}$. A la madre Buainaiño le correspondía preparar la olla de barro donde se tostaría la coca, se cocinaría el tabaco, se prepararía el ají y se haría madurar la yuca, mientras que Kaï Mo debía fabricar el canasto para que al nacer sus hijas tuvieran en qué trastear esos alimentos. De esa manera nació una de las hijas, que surgió del pensamiento, y esa niña es la coca.

La niña salía con su canasto acompañando a su mamá a la chagra 6 , un lugar donde se cultiva y se vive. Mientras Buinaiño sacaba la yuca, la niña extraía de su canasto un espejo y un peine de almendra. Un día, mientras ella se peinaba, dejó caer una pepita -similar a lo que se conoce como una liendre- en la tierra y así dio origen a la mata de coca: fue la primera semilla. Por ello la niña recibió el nombre de Komuyaringo ${ }^{7}$, ya que hacía nacer y crecer a todo lo que tocaba. Al día siguiente, ya había germinado la mata, tenía la primera hoja, larga. Este arbusto ha sido considerado desde épocas ancestrales como sabiduría, hoja de poder, de pensamiento y de inteligencia.

Desde los Andes colombianos y entre los pueblos autóctonos localizados en dirección sur, hasta llegar a la Argentina, la hoja de coca se ha masticado -más o menos- por un lapso de 5.000 años. En algunos casos, como remedio casero para una variedad de enfermedades o como estimulante suave y tónico en condiciones climáticas específicas y de trabajo arduo. Y también,

4 Terminología huitota, pueblo indígena de la Amazonía.

5 Héroe cultural asociado al agua, paradigma del sabedor de la etnia huitota.

6 Lugar donde se cultivan alimentos, hoja de coca y también se vive.

7 Nombre que se le da a la hija de Kaï Mo y Buainaiño. como una práctica asociada a la vida cotidiana y al culto religioso.

El arbusto se cultiva en bosques húmedos subtropicales conocidos como yungas. Estas son zonas de selva montañosa y bosque andino a lo largo del flanco oriental de los Andes centrales del Perú y Bolivia. Tales regiones guardan vínculos ecosistémicos con las selvas pluviales y los bosques lluviosos y tropicales de las tierras bajas de la Amazonía. La altitud más adecuada para el cultivo del arbusto está entre los 1.000 y 2.000 metros de altura sobre el nivel del mar, en donde las precipitaciones oscilan alrededor de los $2.000 \mathrm{~mm}$ (Mateucci y Morello, s.f., 3-7).

Hay variedades cuyo cultivo es viable por fuera de esos rangos, inclusive en suelos no aptos para la producción agrícola. En los que tienen pendientes superiores a 45 grados se garantiza la escorrentía, por ejemplo. En los bosques tropicales donde se cultiva el arbusto de coca, se encuentran varios estratos del mismo. En el bosque de yungas, de clima cálido y húmedo $\mathrm{y}$, por ende, de suelo fértil, ocurren ritmos metabólicos que culminan en la creación de nutrientes. Sin tales aspectos el arbusto de coca no puede desarrollarse y, además, es viable la sucesión secundaria que es la capacidad innata que tienen los bosques tropicales y subtropicales para recuperarse luego de haber padecido algún tipo de alteración (Mateucci y Morello, s.f., p. 6-7).

Se conocen tres especies del arbusto de coca en el territorio colombiano: Erytroxylum Coca, Erytroxylum Novogranatense Hieron variedad Novo, y Erytroxylum Coca variedad Ipadu Plowman. Estas se presentan con nombres como Amarga, Boliviana, Boliviana Negra, Boliviana Blanca, Caucana, Cuarentana, Dulce, Pajarito, Peluceña, Peruana, Punto Rojo o Tingo María (UNODC, 2005, p. XX). Durante el período 2005-2012, Colombia participó con el 46,4\% de las áreas sembradas con el arbusto de coca y reportadas al finalizar cada año -ver Figura $1 a-$, superando a Perú $(35,8 \%)$ y a Bolivia $(17,8 \%)$, que son los demás participantes del mercado. Sin embargo, las áreas efectivamente sembradas son considerablemente superiores si se tiene en cuenta la erradicación manual que se practica 
en los tres países, más la erradicación por aspersión aérea de herbicidas tóxicos, realizada exclusivamente en Colombia, como parte de la política mundial anti-drogas. En la Figura lb se aprecia la diferencia, pues al considerar la erradicación, la participación de Colombia se incrementa sustancialmente al $70,8 \%$.

La producción a partir de hojas de coca y la síntesis química son los procesos más empleados para producir cocaína, y difieren en las técnicas, reactivos y cantidades producidas (UNODC, 2012, p. 13-16). La producción a partir de la hoja de coca no requiere de equipos sofisticados como tampoco de vastos conocimientos en química (CAN, 2013, p. 51), siendo esta la razón por la que la cantidad de megalaboratorios se reduce a medida que la producción se desconcentra y se dispersa bajo la forma de "chagras". No hay economía de escala sustancial en la producción de coca en grandes laboratorios pues, para contrarrestar su exposición al riesgo de incautación y destrucción, los narcotraficantes deben pagar elevadas sumas a través de sobornos, mientras que con la mimetización de pequeñas chagras se evitan tales pagos. Con una tonelada de hoja de coca es posible obtener 1,28 $\mathrm{kg}$ de base de coca y, en el resultado de la cadena en el 2008, las compras de hoja representaron el 8,8\% del negocio, el valor agregado en la producción de la base y el clorhidrato el 20,6\% y las ganancias de los narcotraficantes el restante 70,6\% (Mejía y Rico, 2011, p. 15-40). La primacía colombiana en el tráfico mundial de cocaína continúa explayándose al decir de los flujos de la Figura 2.

La persistencia de las áreas sembradas con el arbusto de coca para usos ilícitos y de los flujos de cocaína originados en Colombia, es un síntoma de la ineficacia de las políticas acordadas en las convenciones internacionales para el control de la oferta de drogas. Una breve revisión del trámite de los acuerdos en tales convenciones, y de la posición de Colombia frente a los mismos, es necesaria a fin de establecer las razones de su escaso poder para incidir en el contenido de los acuerdos.

\subsection{Colombia ante los tratados y la fiscalización internacionales}

Colombia no tuvo representación en la Convención de 1961 que resultó en un acuerdo decisivo para la prohibición (Thoumi, 2017a, p. 147) pues, por ejemplo, creó una instancia cuasi judicial como la Junta Internacional de Fiscalización de Estupefacientes (JIFE), que comenzó a ejercer su mandato en 1968 desde su sede en Viena, Austria.

La limitación del comercio internacional y del uso de sustancias psicoactivas a "fines médicos

Figura 1. Participación de los países andinos en los cultivos de coca, 2005-2012

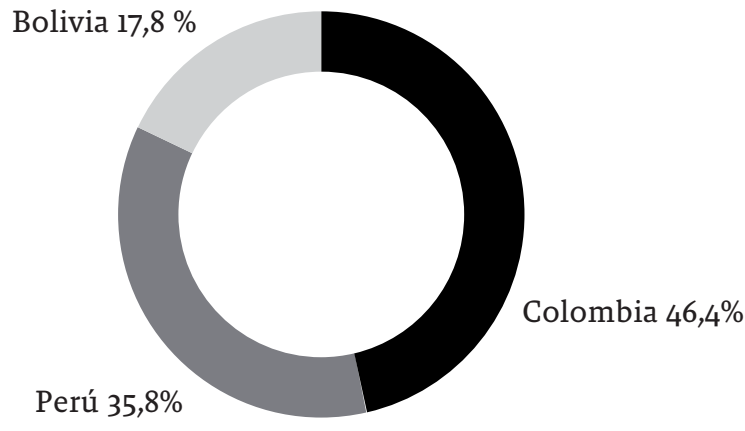

(a) Sin erradicación

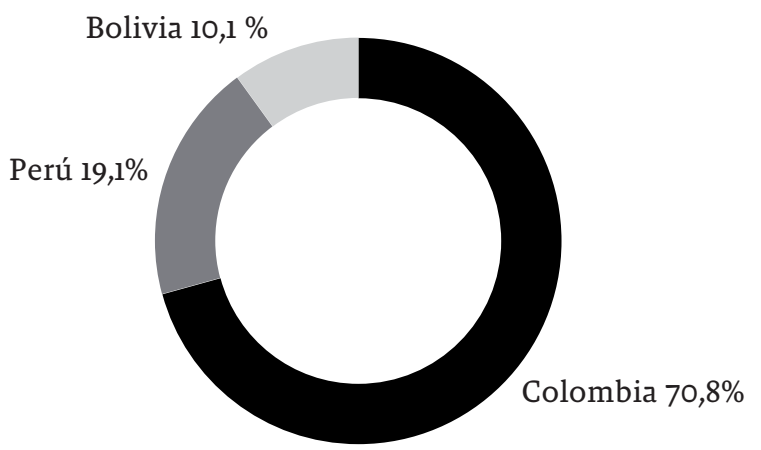

(b) Con erradicación

Fuente: elaborada con base en UNODC (2014, p. 169-172). 
Figura 2. Principales flujos de cocaína en el mundo, 2011-2015

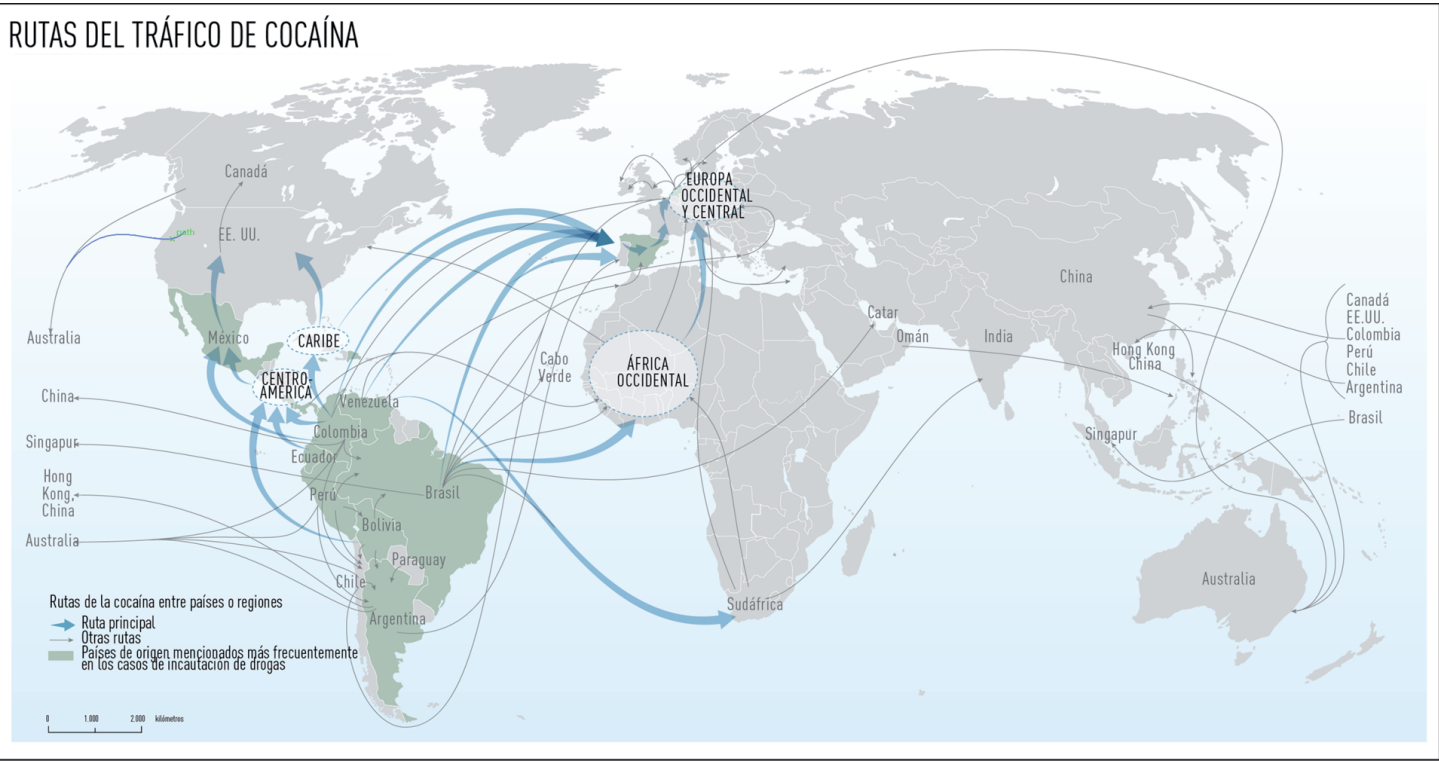

Fuente: tomada de RT - SEPA MÁS (2015).

y científicos" fue la regla en la que insistió Estados Unidos durante las seis convenciones que se realizaron entre 1909 y 1939, motivadas especialmente por el auge de la adicción al opio en China y su tráfico internacional (Thoumi, 2017a, p. 135). El sistema de control fue transferido en los primeros años de posguerra- a la recién creada Organización de las Naciones Unidas mediante un consenso entre potencias, pese a lo cual el tráfico de opio continuó su auge, lo que motivó la imposición de la regla estadounidense en el Protocolo del Opio de 1953. El Sistema Internacional de Control de Drogas se consolidó hacia 1967, luego de superadas las controversias con los Estados Unidos, bajo el liderazgo de la Gran Bretaña en torno a la Convención Única. A esta se adhieren en la actualidad 185 países, que han suscrito otras dos convenciones en 1971 y 1988 (Thoumi, 2017a, p. 136).

"Usos y fines médicos y científicos" es un enunciado carente de significado preciso que, por ameritar múltiples interpretaciones, muchas de ellas contradictorias, ha entorpecido la aplicación de los acuerdos (Thoumi, 2017a, p. 139-146). La flexibilidad subyacente para que los gobiernos actúen eficazmente ante los usos indebidos, es una explicación de fondo para que las intervenciones gubernamentales sean disímiles y no uniformes. Adicionalmente, el incremento sustancial de la propensión a consumir sustancias psicoactivas en el mundo, exige la movilización de una gran cantidad de recursos públicos; algo que motiva a los tomadores de decisión a introducir medidas como el reconocimiento jurídico de la tolerancia a la dosis personal, a trasladar el costo del control a los puntos débiles de la cadena, esto es, al control de la oferta o, de manera alternativa, a omitir deliberadamente la intervención.

En la Sesión Especial de la Asamblea General de las Naciones Unidas Sobre Drogas, celebrada en el 2016, los países latinoamericanos no lograron acuerdos que les permitieran actuar en bloque, quedando expuesta "la falta de coherencia del sistema" (Garzón-Vergara, 2016, p. 5-6). No obstante, se reiteraron los compromisos en materia de fiscalización y, además, en el desarrollo alternativo preventivo y otras "estrategias sostenibles de control de cultivos" (UNGASS, 2016, p. 26). El marco general de tales estrategias se compuso del "no a la guerra a las drogas" y el énfasis en los programas de desarrollo alternativo en 
el contexto socioeconómico inmanente a cada país, encaminados a una solución de largo plazo con los que se superen los programas de sustitución de cultivos. Las críticas cortoplacistas no se hicieron esperar. Por su parte, el gobierno colombiano sugirió "encontrar herramientas para enfrentarlo con un enfoque de salud pública y de promoción del desarrollo humano en un marco de respeto por los Derechos Humanos" (UNODC, 2017d, p. 13).

Si los "usos y fines médicos y científicos" circunscriben el diseño de la política de drogas al ámbito de la medicina y de la ciencia (Thoumi, 2016; 2017a), ese énfasis renovado abre una compuerta a la participación activa de las "ciencias sociales".

Felbab-Brown (2017, p. 325) analiza el fenómeno de la erradicación de la adormidera en Tailandia, que se suspendió hasta que se implementaron "programas de subsistencia alternativos", pari passu a las operaciones de contrainsurgencia y durante algunos años de posconflicto. Tal conjunto de políticas y desarrollos alternativos tuvieron como desenlace la declaración de Tailandia en el 2002 como un país libre de drogas, convirtiéndose en el único que ha eliminado cultivos ilícitos mediante enfoques centrados en la erradicación gradual. Las principales dificultades consistieron en la resistencia a adoptar los cambios institucionales indispensables para erradicar la producción de la adormidera y en la premura con la que se esperaban tales cambios, pues, de hecho, la erradicación completa tomó 30 años luego de iniciada la ejecución de los programas alternativos.

A pesar de que Colombia se ha erigido como el epicentro de la oferta mundial de cocaína, su injerencia en las convenciones internacionales anti-drogas ha sido marginal. De hecho, en momentos decisivos como la adopción del esquema de fiscalización ni siquiera tuvo presencia. Por el contrario, las reglas de los principales países consumidores, que en ocasiones han actuado en bloque, se han impuesto para cargar de responsabilidades en materia de erradicación a los países productores, en desmedro de los esfuerzos que sus programas de salud pública han de realizar en materia de prevención del consumo. En vista de que los acuerdos son vinculantes, dos cuestiones saltan a la vista: ¿cuál ha sido el contenido de las políticas nacionales? y ¿qué tan eficaces han resultado?

\subsection{Contenido de las políticas nacionales y balance de resultados}

Las políticas nacionales para combatir la expansión del arbusto de coca han tomado cuerpo en los Planes Nacionales de Desarrollo -PNDen el marco de los acuerdos internacionales y, además, de la intervención dura de los Estados Unidos. Hacia 1996 se estableció unilateralmente el mecanismo de la certificación. Este vinculaba el tratamiento arancelario y para-arancelario en el comercio exterior de bienes y servicios originados en Colombia, principalmente, al cumplimiento de metas en materia de erradicación. Tal mecanismo fue sustituido por el informe del Departamento de Estado, de cuya severidad se derivan recortes a la ayuda no reembolsable al desarrollo. En los PND -ver Tabla l- se ha transitado paulatinamente de la erradicación forzada, especialmente por la vía de la aspersión aérea con glifosato que alcanzó su cúspide en la transición de las administraciones de Álvaro Uribe hacia el 2006, a los programas de erradicación manual y sustitución que han tenido muchos altibajos.

En el Acuerdo Final para la Terminación del Conflicto y la Construcción de una Paz Estable y Duradera, suscrito entre el Estado colombiano y las FARC en noviembre de 2016, el punto 4 se refiere a la "Solución al Problema de las Drogas Ilícitas". En tal punto reconocen que entre las principales causas del conflicto armado se encuentra la producción y comercialización de drogas ilícitas. Entre las razones para la persistencia del cultivo de coca, amapola y marihuana, se arguyen las condiciones de pobreza extrema, marginalidad de los procesos de desarrollo, la débil presencia estatal en vastas zonas del territorio y, por supuesto, la criminalidad organizada asociada al narcotráfico. Entre los lineamientos para las 
Tabla 1. Las políticas nacionales para el tratamiento de los cultivos de coca, Colombia 1998-2018

\begin{tabular}{c|c}
\hline Administración y PND & ¿Qué dicen los planes de desarrollo? \\
\hline $\begin{array}{c}\text { Andrés Pastrana } \\
\text { (1998-2002): Cambio para construir } \\
\text { la paz. }\end{array}$ & $\begin{array}{c}\text { Incorporó el Plan Colombia que establecía reducir en un } 50 \% \text { el área de los } \\
\text { cultivos y el fortalecimiento de la fuerza pública en la lucha contra el } \\
\text { narcotráfico y el terrorismo. }\end{array}$ \\
$\begin{array}{c}\text { Álvaro Uribe Vélez I } \\
\text { (2002-2006): Hacia un Estado } \\
\text { comunitario. }\end{array}$ & $\begin{array}{c}\text { Trazó lineamentos respecto a la desarticulación del proceso de producción, } \\
\text { comercialización y consumo de drogas, por medio de la aspersión y la } \\
\text { erradicación voluntaria, articulada con programas de desarrollo alternativo } \\
\text { bajo el esquema de subsidios condicionados a la erradicación. }\end{array}$ \\
$\begin{array}{c}\text { Álvaro Uribe Vélez II (2006-2010): } \\
\text { Estado comunitario: desarrollo } \\
\text { para todos. }\end{array}$ & $\begin{array}{c}\text { Propuso combatir las actividades ilícitas y fortalecer el tejido social, reforzar la } \\
\text { lucha contra las drogas bajo el principio de corresponsabilidad, generar } \\
\text { alternativas a los cultivos ilícitos por medio del desarrollo alternativo (Familias } \\
\text { Guardabosques) y desarticular el círculo vicioso } \\
\text { narcotráfico-terrorismo-violencia. }\end{array}$ \\
$\begin{array}{c}\text { Juan Manuel Santos I (2010-2014): } \\
\text { Prosperidad para todos. }\end{array}$ & $\begin{array}{c}\text { Propuso un enfoque de política nacional de erradicación manual y desarrollo } \\
\text { alternativo, por medio de estrategias de fortalecimiento del Estado con el } \\
\text { apoyo de la comunidad internacional y del sector privado. }\end{array}$ \\
$\begin{array}{c}\text { Juan Manuel Santos II (2014-2018): } \\
\text { Todos por un nuevo país. }\end{array}$ & $\begin{array}{c}\text { Adoptón una política con enfoque de derechos y se suspendió la aspersión con } \\
\text { glifosato. En el punto 4 del acuerdo de paz, suscrito con las FARC, se } \\
\text { asumieron compromisos para dar solución al problema de las drogas ilícitas. }\end{array}$ \\
\hline Fuente: elaborada con base en DNP (2018).
\end{tabular}

políticas se resaltan: i) Articulado a la Reforma Rural Integral, se propone la creación de un programa nacional integral de sustitución de cultivos de uso ilícito (PNIS), que debe tener un enfoque territorial y de género, además de reconocer y tener en cuenta las necesidades, características y particularidades económicas, culturales y sociales de los territorios y las comunidades rurales; ii) el PNIS contribuirá con la generación de condiciones que les permitan a las comunidades-que habitan en zonas afectadas por cultivos de uso ilícito- gozar de condiciones de bienestar y buen vivir, tales como el acceso y formalización de la propiedad, adecuación de tierras, vivienda, asistencia técnica, y estímulos a la economía solidaria y cooperativa: iii) el PNIS promoverá la sustitución voluntaria de cultivos de uso ilícito, mediante el impulso de planes integrales municipales y comunitarios de sustitución y desarrollo alternativo, a través de estrategias participativas de desarrollo.

La siembra del arbusto de coca es un negocio cuya extensión precisa se desconoce. El Observatorio de Drogas de Colombia y la UNODC acostumbran dar dos reportes anuales de las áreas sembradas, a través de un monitoreo en los territorios afectados, pero ello es solo la fracción de las áreas sembradas que no se erradicaron, por aspersión aérea o mediante procesos manuales, y que no se cultivaron. Es el inventario de las áreas sembradas al momento de realizarse el monitoreo. De estas últimas es posible estimar una porción a través de las incautaciones de hoja de coca en kilogramos, transformándolas a hectáreas con el uso del rendimiento por región (UNODC, 2016, p. 48), quedando por establecer las áreas cuya producción fue efectivamente transformada en cocaína. Esto último se puede aproximar a escala global a partir de las incautaciones de clorhidrato en el mundo y, sin embargo, es insuficiente, pues se desconoce la cantidad consumida por los 17 millones de cocainómanos y usuarios eventuales.

Las tendencias de los componentes conocidos de la actividad cocalera -Figura 3- revelan, antes que nada, la imposibilidad de que Colombia se libre de los cultivos de coca con un mercado en expansión, esto es, con más consumidores dispuestos a pagar precios más elevados por la droga. Además, son sintomáticas de las 
contradicciones a las que se han visto expuestas las diferentes administraciones. Algo debido al carácter político-aceptante de las responsabilidades en el control del mercado desde su rol de oferentes y, ahora, de consumidores. Los escasos logros del Plan de Desarrollo Alternativo de Samper y su programa bandera, el PLANTE, fueron la antesala del Plan Colombia de la administración Pastrana y el Departamento de Estado de los Estados Unidos. Tal fue el inicio de la escalada de la aspersión aérea con glifosato que llegó a su clímax en la primera administración de Uribe, período durante el que se sembró más que en el de Pastrana.

Familias Guardabosques fue uno de los programas de erradicación y sustitución más eficaces pues, basado en una estrategia de transferencias monetarias condicionadas, similar a la de los programas de lucha contra la pobreza extrema, alcanzó metas considerables, con las que se consiguió aminorar el impacto de la aspersión aérea. A partir del 2008 la estrategia comenzó a desactivarse y el decrecimiento de las áreas monitoreadas a ralentizarse. Las áreas sembradas han vuelto a crecer desde la transición al segundo período de la administración Santos, año en el que la erradicación manual también lo hace, mientras que cesa la aspersión aérea.

Las incautaciones de hoja de coca representan una porción marginal de la actividad cocalera -ver Tabla 2-, pues la época en la que se cambiaban bultos de hoja por otros tantos de dinero en efectivo fueron tan épicas como efímeras. Esto por causa de la desconcentración de la producción en megalaboratorios como "Tranquilandia", destruido por la policía antinarcóticos en marzo de 1984, a chagras de producción

Figura 3. Tendencias de los componentes conocidos de la actividad cocalera en hectáreas, Colombia 1994-2017

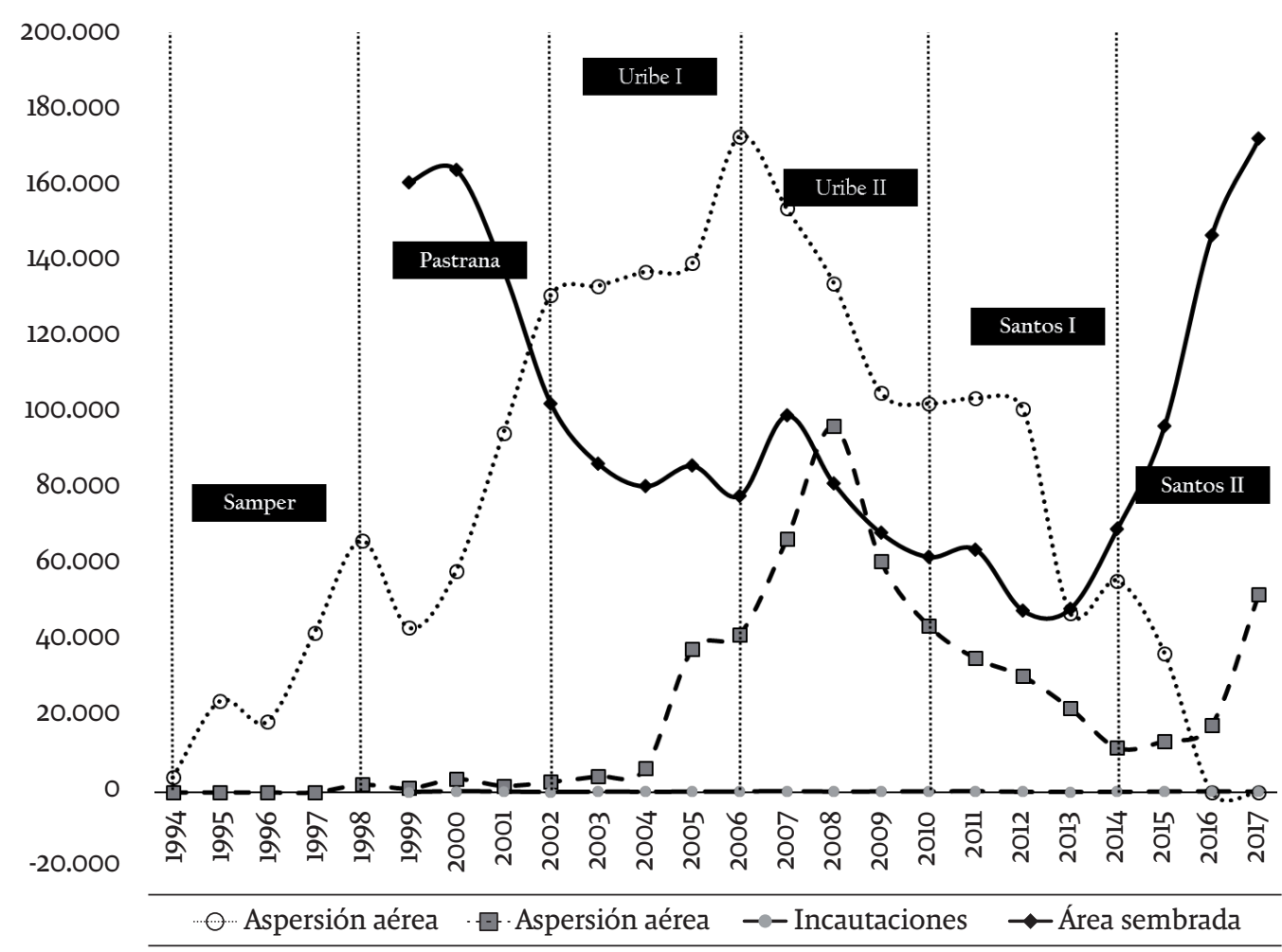

Fuente: elaborada con base en ODC (2018). 
en pequeña escala expuestas al cobro del "gramaje" por las FARC. Es probable que en tal marginalidad también haya influido la corrupción de los organismos del Estado encargados de la vigilancia y el control de las vías. Por su parte, las incautaciones de clorhidrato son una porción relevante de la actividad cocalera, pero no es posible precisar su origen. Salvo en la administración Pastrana, la aspersión aérea con glifosato ha representado la mayor proporción de la extensión de tal actividad, seguida de las áreas sembradas que son monitoreadas al final de cada año y, por último, de la erradicación manual.

Del examen de las Figuras 4 a 8 se infiere, en primer lugar, que las zonas con suelo infértil como las de la Alta Guajira, así como aquellas con tasas de urbanización más elevadas, que son las que presentan menores índices de pobreza y mejores índices de desarrollo, han estado al margen de la actividad cocalera. Esto a no ser por el incremento en las incautaciones de clorhidrato de cocaína que, además de los puertos, se ha focalizado en las zonas metropolitanas. En segundo lugar que, como resultado de la promoción de los cultivos comerciales de arbusto de coca por parte de los narcotraficantes, se capta una tendencia a la reducción de la escala de los cultivos. Algo constatable en la recomposición de la amplitud de los rangos de cada cuartil en las mismas figuras. Y, por último que, no obstante cierta continuidad en las zonas de actividad cocalera, hay relevos significativos en los municipios con mayor actividad entre administraciones. Fenómeno que induce a formular la hipótesis de la trashumancia regional del cultivo del arbusto de coca.

Durante la administración Pastrana -ver Figura 4- el cuartil con las áreas más elevadas estuvo conformado por Orito, Valle del Guamuez y Puerto Asís en el Putumayo, Miraflores en el Guaviare, Tibú en Norte de Santander y Cartagena del Chairá en el Caquetá. Durante la primera administración Uribe -ver Figura 5-, la actividad cocalera más intensa se localizó en Tumaco (Nariño) y en San José del Guaviare. Durante su segundo período -ver Figura 6-, de nuevo en Tumaco y en Cumaribo (Vichada). En la primera administración Santos -ver Figura 7- se puso en evidencia una nueva estrategia de los narcotraficantes. Esta abarcó otra vez a Tumaco y a poblaciones nariñenses vecinas como Roberto Payán, Barbacoas y Magüí, a Puerto Asís (Putumayo) y a Miraflores -seguido de cerca el último por sus vecinos El Retorno y San José del Guaviare- y consistió en reducir las grandes extensiones de los cultivos, de períodos precedentes, a fragmentos de menor escala. Durante el segundo período de la administración Santos, tal estrategia se combinó con la concentración de las mayores extensiones de la actividad cocalera en municipios reconocidos por la presencia de grupos armados irregulares como Tumaco y Tibú -ver Figura 8- y, en menor medida, en Puerto Asís y en El Tambo (Cauca).

En relación con el esfuerzo internacional, el esfuerzo nacional en materia de incautaciones de clorhidrato se duplicó en los últimos veinte años. Durante la administración Pastrana en

Tabla 2. Aproximación a la extensión de la actividad cocalera (ha) por administración, Colombia 1999-2017

\begin{tabular}{|c|c|c|c|c|c|c|}
\hline \multirow[t]{2}{*}{ Administración } & \multirow[t]{2}{*}{ Aspersión Aérea } & \multirow{2}{*}{$\begin{array}{c}\text { Erradicación } \\
\text { Manual }\end{array}$} & \multicolumn{2}{|c|}{ Incautaciones* } & \multirow{2}{*}{$\begin{array}{c}\text { Área } \\
\text { Sembrada** }\end{array}$} & \multirow[t]{2}{*}{ Total } \\
\hline & & & Hoja de coca & Clorhidrato & & \\
\hline A. Pastrana & 325.702 & 9.056 & 560 & 57.723 & 562.399 & 955.439 \\
\hline A. Uribe I & 580.169 & 89.322 & 590 & 89.401 & 330.301 & 1.089 .783 \\
\hline A. Uribe II & 493.341 & 266.763 & 736 & 102.229 & 309.690 & 1.172 .759 \\
\hline J. M. Santos I & 306.435 & 99.481 & 534 & 117.312 & 228.874 & 752.637 \\
\hline J. M. Santos II ${ }^{* *}$ & 36.494 & 83.117 & 512 & 192.125 & 413.729 & 725.967 \\
\hline
\end{tabular}

Notas: $\left(^{*}\right)$ Equivalentes en hectáreas; $\left(^{* *}\right)$ Resultados del monitoreo al finalizar cada año.

Fuente: elaborada con base en ODC (2018). 
Figura 4. La extensión de la actividad cocalera durante la administración Pastrana
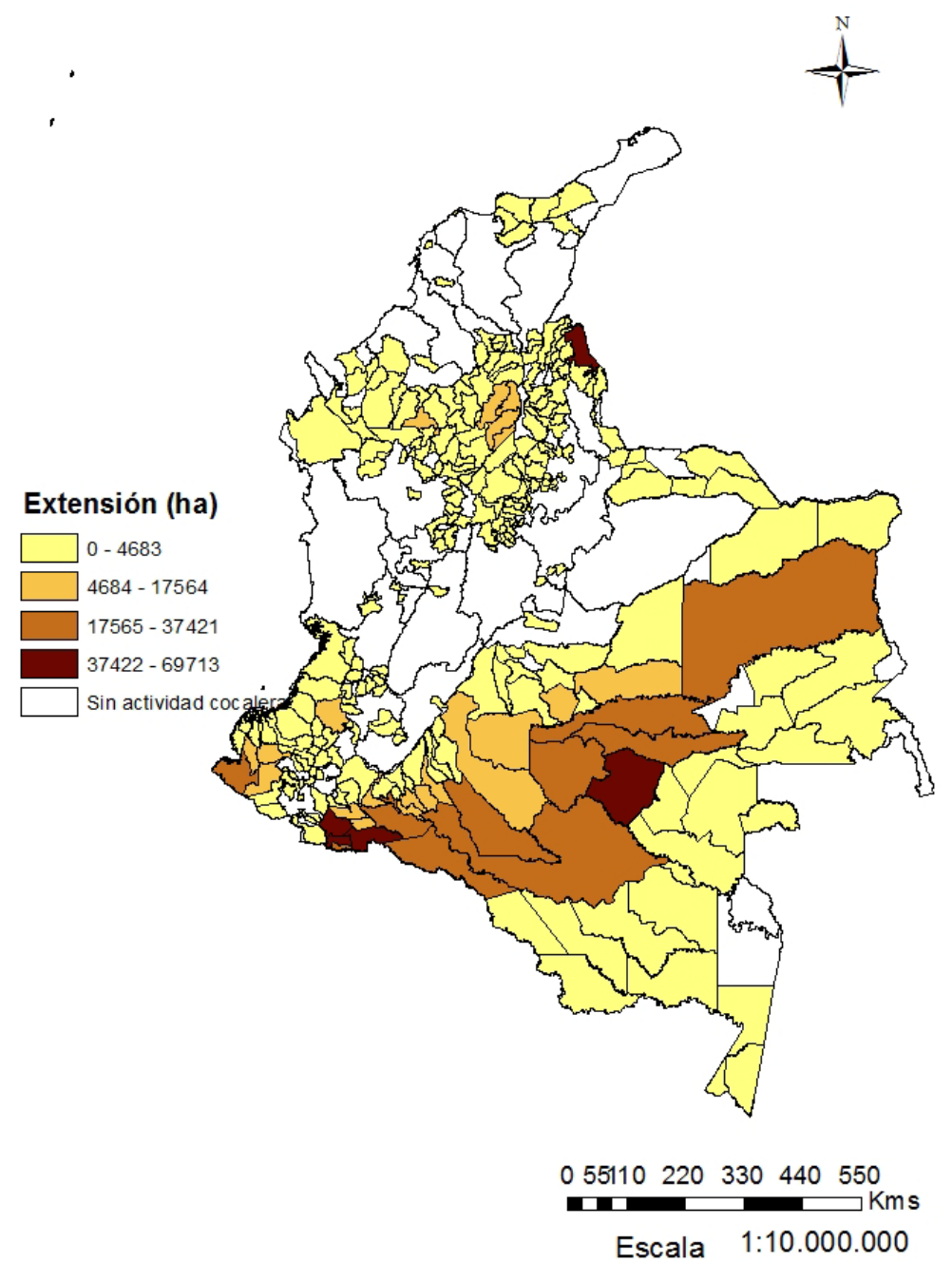

Fuente: elaborada con base en ODC (2018).

Colombia se incautaron -en promedio- dos kilos de clorhidrato por cada kilo incautado en el exterior, mientras que en la segunda administración de Santos esa razón osciló entre 4 y 5 veces más. Por su parte, el uso del glifosato en la erradicación del arbusto de coca, vía aspersión aérea, es cuestionado por sus efectos severos sobre la salud de quienes entran en contacto con el herbicida, y también por sus externalidades negativas sobre el ambiente. En el mismo sentido, en los municipios objeto de la aspersión aérea con glifosato los males sociales y ambientales no se han reducido, sino que, por el contrario, persisten a una escala superior que cuando no se realizaban fumigaciones en el país. 
Figura 5. La extensión de la actividad cocalera durante la primera administración Uribe



Fuente: elaborada con base en ODC (2018).

\subsection{Caracterización de los municipios objeto de la aspersión}

Los males socioambientales asociados a la salud y a la deforestación, y los políticos relacionados a la violencia, que padecen los colombianos, son más agudos en las zonas afectadas por la aspersión aérea con glifosato. La caracterización de los municipios con aspersión aérea se hace empleando una taxonomía con la que se busca captar la intensidad de tal actividad, asociándola con el área fumigada. En relación con la violencia, su expresión más conspicua es la tasa de homicidios por cada 100.000 habitantes que, tal como se explica en la Tabla 3, es más elevada cuanto mayor sea el área afectada con la aspersión aérea y, además, es superior a la del resto del país no fumigado. Son varias 
Figura 6. La extensión de la actividad cocalera durante la segunda administración Uribe

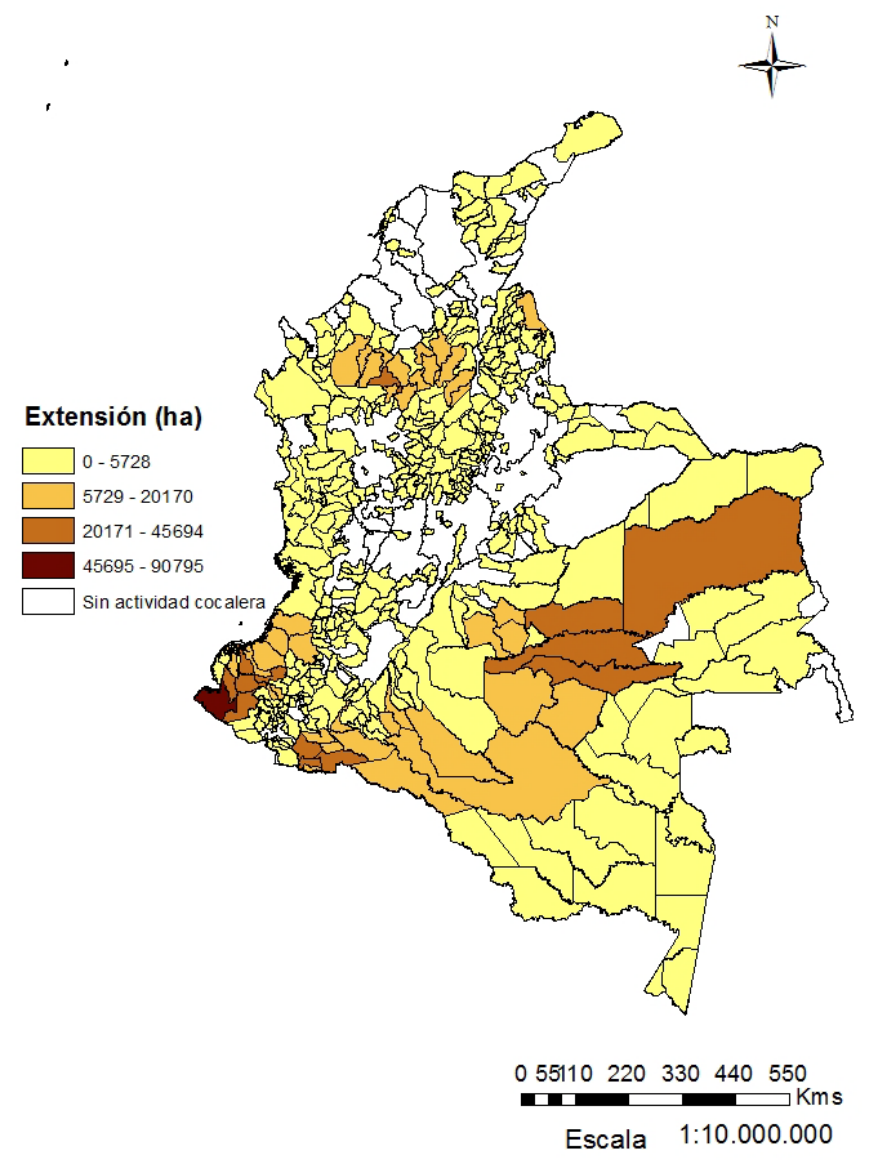

Fuente: elaborada con base en ODC (2018).

Tabla 3. Tasa de homicidios por cada 100.000 habitantes por tipo de municipios, Colombia 2005-2015

\begin{tabular}{lcccc}
\hline \multicolumn{1}{c}{ Tipo de municipios } & Número de Municipios & $\mathbf{2 0 0 5}$ & $\mathbf{2 0 1 0}$ & $\mathbf{2 0 1 5}$ \\
\hline Municipios con aspersión aérea & 235 & 45 & 56 & 24 \\
$\quad$ Muy elevada & 25 & 64 & 77 & 35 \\
$\quad$ (Más de 20.000 ha) & 35 & 39 & 68 & 30 \\
$\begin{array}{l}\text { Elevada } \\
\text { (Entre 5. 000 ha y 19.999 ha) }\end{array}$ & 175 & 44 & 53 & 23 \\
$\quad$ Promedio & 887 & 39 & 33 & 24 \\
$\quad$ (De 0,01 a 4.999 ha) & 1.122 & 40 & 38 & 24 \\
\hline Resto del país & & & & \\
\hline
\end{tabular}

Fuente: elaborada con base en ODC (2018) y FORENSIS (2018). 
Figura 7. La extensión de la actividad cocalera durante la primera administración Santos

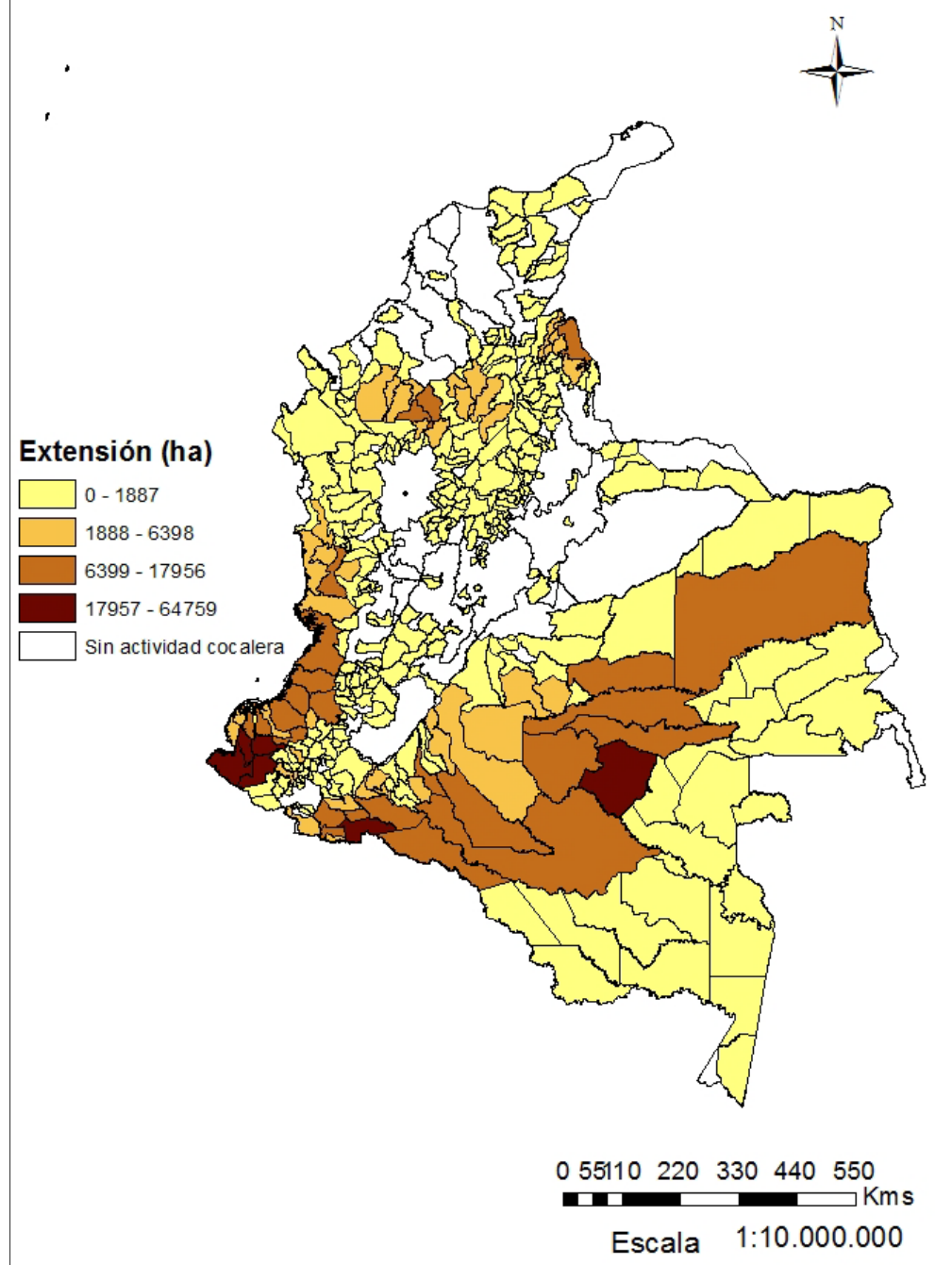

Fuente: elaborada con base en ODC (2018).

las razones que explican esta asociación tendencial de variables, pero el interés de la caracterización es presentar una regularidad estadística espacial y temporal que pone en duda la sabia decisión de emplear este método para erradicar el arbusto de coca.

A la "superficie que permanece cubierta por el bosque natural tanto al inicio como al final del período de análisis", el Sistema de Información Ambiental de Colombia lo denomina como bosque estable, y la reducción de su área es una medida de deforestación. Los cambios en el área del bosque estable de la Tabla 4 muestran que, entre el 2000 y el 2010, la deforestación campeó en todo el país, situación que se revirtió entre el 2010 y el 2015 en los municipios menos afectados con la aspersión 
Figura 8. La extensión de la actividad cocalera durante la segunda administración Santos*



Fuente: elaborada con base en ODC (2018).

aérea y en el país no fumigado en donde, por el contrario, hay evidencias de reforestación. La intensidad y la persistencia de la deforestación del bosque estable en los municipios con aspersión aérea muy elevada o elevada, es sintomática de la limitada resiliencia de tales ecosistemas a los efectos de la fumigación.

El glifosato "es el herbicida más producido en el mundo, con evidencia de ser causante del Linfoma No Hodgkin -LNH- en humanos y evidencia suficiente en animales, evidencia mecanicista de genotoxicidad y estrés oxidativo, que apoyan la clasificación 2A de la Agencia Internacional para la Investigación del Cáncer" (Guyton et al., 2015, pp. 490-491). Monsanto manifestó su "firme desacuerdo" con el dictamen de la IARC, aportando trece testimonios de prestigiosas agencias 
Tabla 4. Variaciones absolutas (+/-) del bosque estable por tipo de municipios, Colombia 2000-2015

\begin{tabular}{l|cc|cc|cc}
\hline \multirow{2}{*}{ Tipo de municipios } & \multicolumn{2}{|c|}{ 2005-2000 } & \multicolumn{2}{c|}{ 2010-2005 } & \multicolumn{2}{c}{ 2015-2010 } \\
\cline { 2 - 7 } & Área (ha) & $\%$ & Área (ha) & $\%$ & Área (ha) & $\%$ \\
\hline Municipios con aspersión aérea & $-682.860,9$ & $-44,9$ & $-700.689,6$ & $-57,4$ & $199.845,7$ & 40,8 \\
$\quad$ Muyy elevada & $-296.443,3$ & $-19,5$ & $-225.249,8$ & $-18,4$ & $-167.072,9$ & $-34,1$ \\
$\quad$ (Más de 20.000 ha) & $-143.601,0$ & $-9,5$ & $-154.510,8$ & $-12,6$ & $-58.741,6$ & $-12,0$ \\
$\quad \begin{array}{l}\text { Elevada } \\
\text { (Entre 5. 000 ha y 19.999 ha) }\end{array}$ & $-242.816,6$ & $-16,0$ & $-320.929,0$ & $-26,3$ & $425.660,2$ & 86,8 \\
$\quad \begin{array}{l}\text { Promedio } \\
\text { (De 0,01 a 4.999 ha) }\end{array}$ & $-836.673,8$ & $-55,1$ & $-520.918,4$ & $-42,6$ & $290.322,7$ & 59,2 \\
Resto del país & $-1.519 .534,7$ & $-100,0$ & $-1.221 .608,0$ & $-100,0$ & $490.168,4$ & 100,0 \\
\hline Total & & & & & \\
\hline
\end{tabular}

Fuente: elaborada con base en ODC (2018) y IDEAM (2018).

estatales y académicas de todo el mundo $\mathrm{y}$, además, el informe de consultoría de la Consultora de Ciencia y Regulación INTERTEK basado en otro panel de expertos. Desacuerdo que recalca en la sentencia de la Autoridad Europea en Seguridad de los Alimentos -EFSA- para quienes "es poco probable que el glifosato presente un peligro cancerígeno para los seres humanos y la evidencia no apoya la clasificación con respecto a su potencial carcinogénico" (Monsanto, 2015, p. 1). Los científicos de la Universidad de Birmingham (Sorahan, Williams, Aardema y Acquavella, 2016, p. 16) llegaron a la misma conclusión luego de estudiar la fiabilidad de los resultados de los paneles de expertos. De nada valieron estos contraargumentos ni los 800 estudios adicionales que dice poseer Monsanto, entre ellos uno de la Agencia de Protección Ambiental de los Estados Unidos -EPA-, para la justicia del Estado de California que, a comienzos de agosto de 2018, le impuso a la multinacional una condena de US\$289 millones en favor de Dwayne Johnson, jardinero de San Francisco con LNH atribuido a su exposición al glifosato. Debido a que algo más de 2.000 demandas compensatorias y por daños cursan en diferentes tribunales del mundo, el precio en bolsa de la farmacéutica alemana Bayer, que absorbió a Monsanto, cayó al punto que reportaron pérdidas por 11.000 millones de euros con posterioridad al fallo en California.

El Instituto Nacional de Salud (2015) analizó los resultados de la IARC a la luz del principio de precaución empleado por la Corte Constitucional en varias sentencias, fundado especialmente en la probabilidad de daño potencial grave e irreversible, y el principio de certeza científica. Por ser parcial el principio de certeza científica y no contar con evidencia de daño irreversible, así este exista, el Instituto consideró que no era viable acogerse al principio de precaución en el escenario de suspensión de la aspersión aérea de los cultivos de coca con glifosato. El clímax de esta aspersión aérea ocurrió entre el 2005 y el 2006. A las personas encuestadas durante el operativo censal del 2005 se les preguntó si en los cinco años precedentes habían sido objeto de tratamiento con quimioterapia. Los resultados de la Tabla 5 indican que la probabilidad de tener algún linfoma, a la luz de los casos de tratamiento con quimioterapia, es 3,1 veces superior entre los habitantes de zonas rurales que han sido objeto de la aspersión aérea que en aquellos que no lo han sido. Tal probabilidad se incrementa a 10,3 si se compara con los municipios en donde la aspersión aérea ha sido muy elevada.

Estas regularidades estadísticas confirman que Colombia asume unos costos inconmensurables en el combate contra los cultivos ilícitos, por situarse como el epicentro mundial de la oferta de cocaína. La violencia, el ambiente y la salud se deterioran de forma coetánea en los municipios que han sido objeto de la aspersión aérea con glifosato. Sin embargo, y luego de al 
Tabla 5. Tasa de casos de quimioterapia por cada 100.000 habitantes de las zonas rurales, Colombia 2005

\begin{tabular}{lccc}
\hline \multicolumn{1}{c}{ Tipo de municipios } & Número de casos & $\begin{array}{c}\text { Población en } \\
\text { zonas rurales }\end{array}$ & $\begin{array}{c}\text { Tasa por 100.000 } \\
\text { habitantes rurales }\end{array}$ \\
$\begin{array}{l}\text { Municipios con aspersión aérea } \\
\quad \text { Muy elevada }\end{array}$ & 19.767 & 2.653 .561 & 745 \\
$\quad$ (Más de 20.000 ha) & 8.668 & 346.833 & 2.499 \\
$\quad \begin{array}{l}\text { Elevada } \\
\text { (Entre 5. 000 ha y 19.999 ha) }\end{array}$ & 1.718 & 283.244 & 607 \\
$\quad \begin{array}{l}\text { Promedio } \\
\text { (De 0,01 a 4.999 ha) }\end{array}$ & 9.381 & 2.023 .484 & 464 \\
$\begin{array}{l}\text { Resto del país } \\
\text { Total }\end{array}$ & 17.492 & 7.231 .676 & 242 \\
\hline
\end{tabular}

Fuente: elaborada con base en ODC (2018) y DANE (2018).

menos 20 años de su uso y del uso de otros instrumentos para acabar con el negocio cocalero, este continúa expandiéndose; es decir, la ineficacia del glifosato es flagrante: ¿por qué? En el siguiente acápite se ofrece una explicación tentativa a esta cuestión.

\section{La trashumancia de los cultivos del arbusto de coca}

En el primer acápite de este artículo se argumentó que el mercado mundial de la cocaína no cesa de expandirse, y en el segundo que es muy fácil producirla y que las políticas de erradicación del arbusto de coca, especialmente la de aspersión aérea con glifosato, acarrean enormes costos socioambientales y políticos, sin que el negocio cocalero se resienta. La principal razón para que ello ocurra es que, en vista de las variedades del arbusto, de la universalización de las tecnologías para cristalizar y de la consecuente dispersión territorial de la producción, los esfuerzos de erradicación son inocuos delante de la trashumancia de tales cultivos.

Nociones como la de la agricultura itinerante o la de los cultivos migratorios han sido muy difundidas desde el trabajo seminal de Conklin (1957), para referirse a cultivos de tala y quema del bosque húmedo tropical que luego se transforman en barbecho, por un lapso al final del cual la tierra recupera su fertilidad. Weinstock
(1983) encontró que el incremento en la fertilidad es generalmente superior al requerido para la subsistencia; es decir, que el agricultor obtiene excedentes con esta práctica y, además, que la estabilidad ecológica se alcanza cuando el barbecho perdura por lapsos de entre 7 y 15 años, y los cultivos apenas ocupan el suelo por no más de dos años.

A diferencia de las anteriores nociones, la trashumancia se asocia con cierta modalidad de pastoreo estacional, que consiste en que los rebaños se desplazan de manera incesante en busca de pasto para alimentarse. Un movimiento sujeto a su adaptabilidad a las severas condiciones cambiantes del clima. El promotor comercial de la siembra del árbol de coca, el narcotraficante, se asemeja al vaquero que moviliza su rebaño hacia las tierras bajas en invierno para luego retornar a las zonas encumbradas en verano. Las políticas de erradicación son como el gélido invierno que arrasa con los pastizales. Sin embargo, así como los cuadrúpedos se adaptan a las condiciones cambiantes del clima, las variedades del arbusto de coca permiten su cultivo en ecosistemas diversos. Los costos del trashumo de ganado encuentran en su pérdida de peso el principal componente, que es cubierto en buena medida por el crecimiento del rebaño; esto es, menos peso del hato, pero más becerros. El costo del trashumo del arbusto de coca se cubre con la evasión de las incautaciones y 
fumigaciones, y la consecuente obtención de un producto para un mercado de cocaína en expansión; esto es, por la llegada de más consumidores potenciales con capacidad de pago para asumir precios elevados por el alcaloide.

La hipótesis nula es que el conjunto de áreas de la actividad cocalera se distribuye de manera aleatoria en el territorio colombiano. Los resultados de la Tabla 6 sugieren que hay evidencia geoestadística suficiente para rechazarla $y$, en cambio, se admite la hipótesis alterna consistente en que tal distribución de los cultivos de arbusto de coca sigue patrones de conglomeración captados a través de indicadores de autocorrelación espacial. Los conglomerados de valores positivos muy elevados $(\mathrm{HH})$ indican que es hacia esos municipios a donde se trasladó la actividad cocalera y, de manera coetánea, los conglomerados de valores muy bajos o negativos (LL) son los municipios en los que se concentraron las actividades de erradicación. Es muy probable que los casos en los que se detecta la proximidad de valores positivos con negativos (HL), o viceversa (LH), correspondan al fenómeno de continuidad, tozudamente analizado por UNODC, a excepción de Tumaco que es el municipio con mayor continuidad a gran escala de la actividad cocalera.

La administración Pastrana legó a la de Uribe una actividad cocalera en auge en la región selvática, particularmente en el Putumayo, cuyos municipios pasaron a ser el epicentro de la erradicación -ver conglomerado LL en la Figura 9-. Junto con Orito (-57.968 ha), Valle del Guamuez (-37.186 ha), Puerto Asís (-33.458 ha), San Miguel (-24.975 ha), Puerto Guzmán (-17.351 ha), Puerto Caicedo (-13.574 ha), Leguízamo
(-11.461 ha) y Villagarzón (-4.254 ha), municipios del departamento de Putumayo. Las mayores extensiones erradicadas se extendieron a sus vecinos de Miraflores (-27.245 ha) en el Guaviare y de Cartagena del Chairá (-26.161 ha) y de Curillo (-19.988 ha) en el Caquetá. Los procesos de erradicación más intensos se extendieron hasta Tibú (-34.493 ha), en las espesuras del Catatumbo, aunque de forma aislada.

Mientras que los esfuerzos de erradicación del gobierno Uribe se dirigieron con particular intensidad hacia estos municipios de la región selvática, la promoción mercantil del arbusto de coca por parte de los narcotraficantes se relocalizó en los municipios nariñenses de Tumaco (74.088 ha), Magüí (26.831 ha), Roberto Payán (24.159 ha), Barbacoas (2l.344 ha) y El Charco (15.835 ha); en los antioqueños de Tarazá (22.730 ha) y Cáceres (8.813); en los metenses de Puerto Rico (25.324 ha), Vista Hermosa (20.551 ha), Mapiripán (14.975 ha) y Puerto Lleras (11.119 ha); y a San José del Guaviare (21.561 ha) -ver conglomerados HH en la Figura 9-. Siguiendo el lenguaje gaucho de la trashumancia, los narcotraficantes enfrentaron la "invernada" en la región selvática con una "veraneada" en Nariño, Antioquia y el Meta.

La actividad cocalera conocida se incrementó durante el primer mandato de Uribe en $14,1 \%$-ver Tabla 2-, aunque las áreas monitoreadas al final de cada año se contrajeron tal como deseaba el gobierno de los Estados Unidos. Al concluir su segundo mandato la expansión del negocio cocalero se ralentizó, pues tan solo lo hizo a una tasa de $7,6 \%$, debido especialmente al descenso en las áreas objeto de la aspersión con glifosato, y a una leve contracción de las áreas monitoreadas.

Tabla 6. Índice de Moran de los cambios en el negocio cocalero por administración, Colombia 1999-2017*

\begin{tabular}{ccccc}
\hline Transición de administración & Índice de Moran & Valor de z & p-value & Distribución geo-espacial \\
\hline De Pastrana a Uribe I & 0,080907 & 8,592075 & 0,000000 & Conglomerado \\
De Uribe I a Uribe II & 0,057452 & 6,565287 & 0,000000 & Conglomerado \\
De Uribe II a Santos I & 0,085736 & 9,091981 & 0,000000 & Conglomerado \\
De Santos I a Santos II & 0,040585 & 3,921400 & 0,000088 & Conglomerado \\
\hline
\end{tabular}

Nota: $\left(^{\star}\right)$ Hasta diciembre de 2017.

Fuente: elaborada con base en ODC (2018). 
Figura 9. Concentración espacial de las zonas con elevadas extensiones erradicadas y con grandes plantaciones de arbusto de coca entre las administraciones de Pastrana a Uribe I

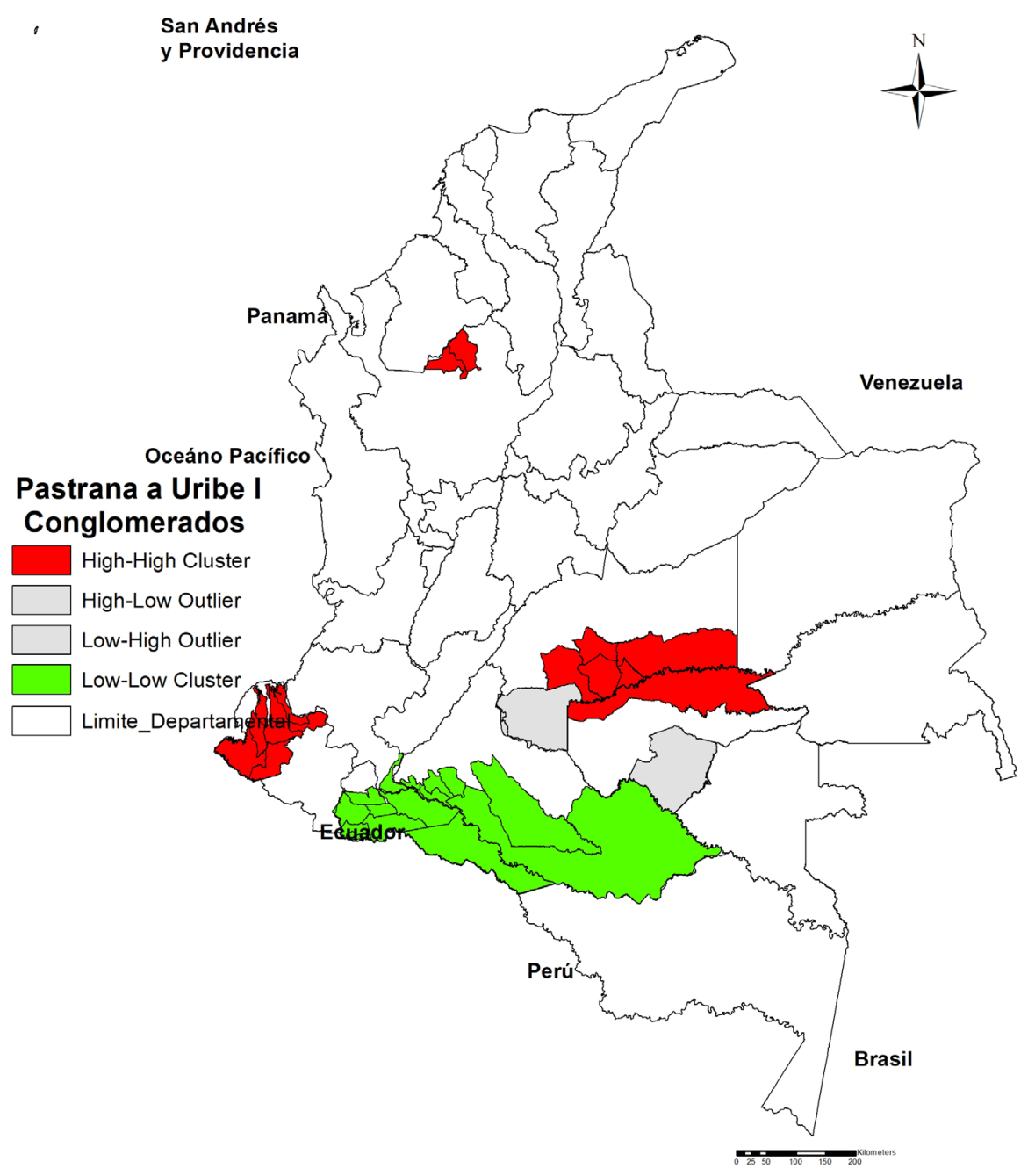

Fuente: elaborada con base en ODC (2018).

Las acciones de erradicación se focalizaron en municipios del Meta, del Guaviare y, en menor medida, de Arauca -ver conglomerados LL de la Figura 10-. Puerto Rico (-17.335 ha), Puerto Concordia (-8.038 ha), Puerto Lleras (-6.609 ha) y Vista Hermosa (-4.099 ha) en el Meta; y Miraflores (-14.625 ha), San José del Guaviare (-13.753 ha), Calamar (-12.314 ha) y El Retorno (-12.248 ha) en el Guaviare, conformaron el principal objetivo de la erradicación. Arauquita (-15.278 ha) y Fortul (-1.764 ha); Tibú (-12.542 ha) en Santander, Tumaco (-11.337 ha) en Nariño y Tarazá (-5.171 ha) en Antioquia, fueron igualmente objetivos de tales acciones, aunque sin involucrar casos de magnitud similar entre los municipios colindantes. 
La actividad cocalera retornó al Putumayo en los municipios de Puerto Asís $(14,683 \mathrm{ha}$ ), Orito (13.399 ha), Puerto Caicedo (4.863 ha), San Miguel (4.480 ha) y Villagarzón (4.138 ha) -ver conglomerados HH en la Figura 10-; se desplazó hacia el andén medio del Pacífico involucrando a los municipios caucanos de Timbiquí (17.040 ha), Guapi (12.057 ha), López (7.783 ha) y El Tambo (5.497 ha), y a los nariñenses de El Charco (9.378 ha), Olaya Herrera (8.513 ha), Policarpa (7.325 ha) y Santa Bárbara (5.679 ha). Además, se ensanchó en el nordeste antioqueño en las jurisdicciones de El Bagre (10.649 ha), Valdivia (3.843 ha), Cáceres (3.809 ha) y Nechí (3.349 ha) e involucró a otros municipios colindantes como Puerto Libertador ( 9.842 ha) y Montelíbano (6.758 ha) de Córdoba y Montecristo (8.581 ha) de Bolívar. La misma escalada cocalera que inició en torno al Nudo de Paramillo, durante este período, también comenzó a florecer en el municipio con mayor extensión territorial del país: Cumaribo (16.802 ha) en el Vichada.

El legado de la administración Uribe al nuevo mandatario era bien conocido debido a que Santos fue su Ministro de Defensa. No es de extrañar entonces que allí, en donde la actividad cocalera había retornado, se hubiese centrado el objetivo de la erradicación durante su primer mandato, en el cual la actividad cocalera conocida se contrajo en $35,8 \%$. ¿Se sembró menos o se produjo más? No es posible responder con certeza a esta cuestión. Lo cierto es que, a excepción de las incautaciones de clorhidrato, los demás componentes conocidos del negocio cocalero se redujeron, lo que indica un viraje en la política que centrará sus acciones -precisamente- en las incautaciones del alcaloide.

El floreciente negocio cocalero en Cumaribo $(-35.828 \mathrm{ha})$ fue el principal objetivo de la erradicación, aunque de forma aislada -ver atípicos HL o LH en la Figura ll-. Las acciones de erradicación se intensificaron en Tumaco (-26.035 ha), El Charco (-16.882 ha), Olaya Herrera (-12.469), Roberto Payán (-10.171 ha), Policarpa (-9.238 ha), Magüí (-8.505 ha) y Santa Bárbara (-6.923 ha) en Nariño; en Tarazá (-19.875 ha), El Bagre (-12.133 ha), Valdivia (-7.590 ha), Zaragoza (-6.933 ha), Cáceres (-6.100 ha) y Anorí (-4.981 ha) en Antioquia y su colindante Puerto Libertador (-12.721 ha) en Córdoba; en San José del Guaviare (-19.782 ha) y en sus vecinos Mapiripán (-17.182 ha), Vista Hermosa (-16.351 ha), Puerto Rico (-12.001 ha) y Puerto Lleras (-6.340) del Meta; y en Valle del Guamuez (-18.004 ha), Orito (-13.556 ha), San Miguel (-10.259 ha), Puerto Asís (-9.757 ha) y Puerto Guzmán (-7.518 ha) en el Putumayo.

La estrategia de la trashumancia de los narcotraficantes hizo que estas zonas fueran relevadas por los municipios chocoanos de Istmina (11.869 ha), Medio San Juan (4.103 ha), Nóvita (3.888 ha), Alto Baudó (2.437 ha), Medio Baudó (2.321 ha), El Litoral de San Juan (1.857 ha), Bajo Baudó (1.538 ha) y Riosucio (1.370 ha); a los nortesantandereanos de Sardinata (4.571 ha) y Convención (1.222 ha); así como de manera aislada por Miraflores (4.868 ha) en el Guaviare, La Macarena (2.211 ha) en el Meta y Buenaventura (1.962 ha) en el Valle del Cauca.

Durante el segundo período de la administración Santos, los esfuerzos de erradicación se desplegaron hacia los municipios chocoanos de Istmina (-11.657 ha), Nóvita (-3.819), Bajo Baudó (-3.039 ha), Alto Baudó (-3.010 ha) y Medio Baudó (-2.425 ha); hacia el metense de Mapiripán (-6.601 ha) y sus vecinos del Guaviare como Miraflores (-13.459 ha), San José del Guaviare (-10.247 ha), El Retorno (-8.336 ha) y Calamar (-5.928); y de forma más aguda hacia los nariñenses de Magüí (-18.816 ha), Roberto Payán $(-18.089 \mathrm{ha})$ y Barbacoas $(-13.141 \mathrm{ha})$ y sus vecinos caucanos de Timbiquí (-11.434 ha), Guapi (-6.853 ha) y López (-3.186 ha) -ver Figura 12-.

Mientras que en los municipios nariñenses y caucanos mencionados se erradicaba el arbusto de coca con evidente intensidad, no menos intensa era su extensión en los colindantes Tumaco (14.456 ha) y El Tambo (8.095 ha). En contraste, la actividad cocalera se explayó en las selvas del Catatumbo, involucrando a Tibú (21.988 ha), El Tarra (7.712 ha), Teorama (3.857 ha) y Sardinata (2.985). Mientras tanto, resurgió de manera aislada en Tarazá (5.478 ha) en Antioquia, La Macarena (5.436 ha) en el Meta y San Miguel (5.209 ha) en el Putumayo. 
Figura 10. Concentración espacial de las zonas con elevadas extensiones erradicadas y con grandes plantaciones de arbusto de coca entre las administraciones de Uribe I a Uribe II

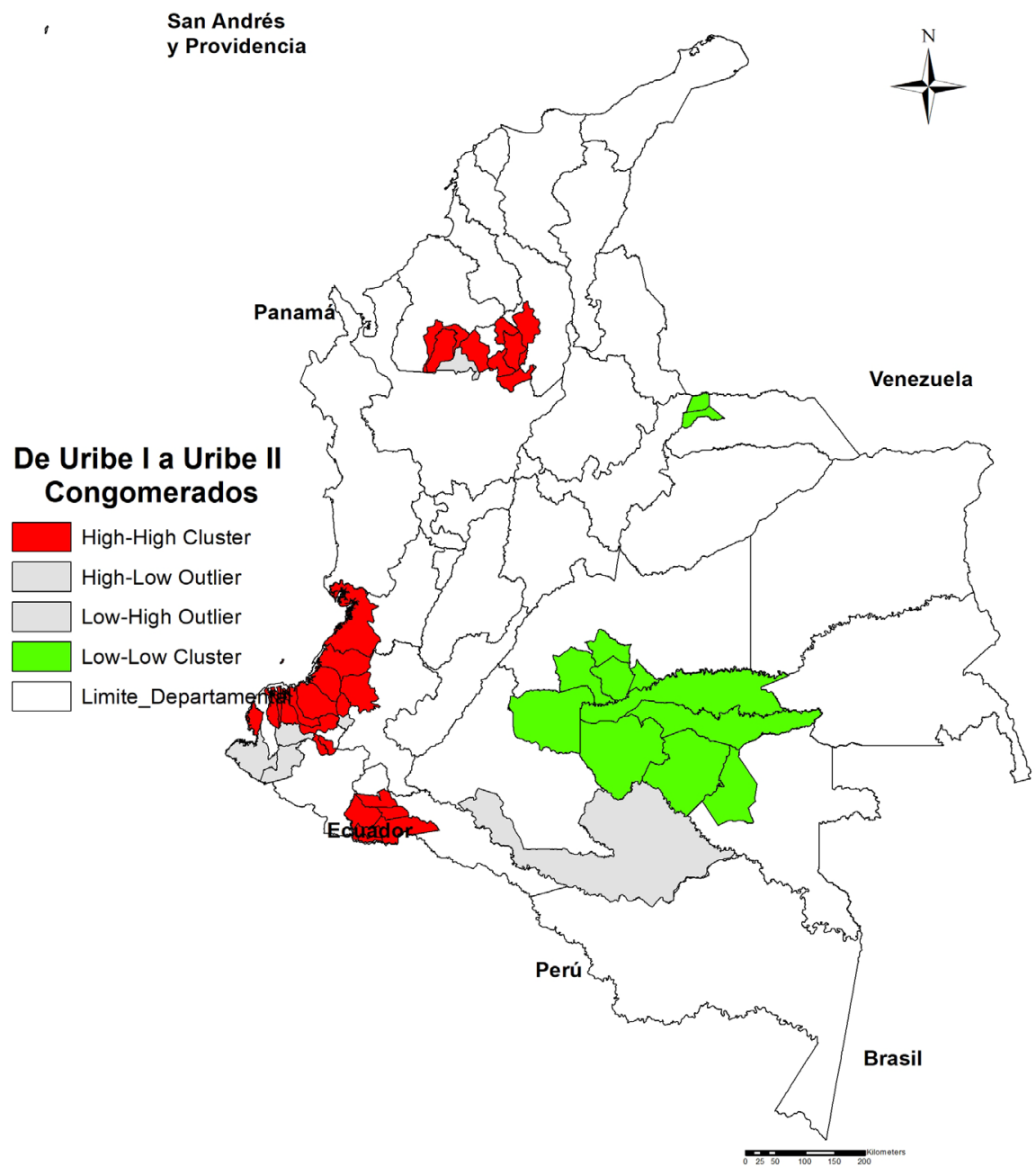

Fuente: elaborada con base en ODC (2018).

Mientras que el Estado colombiano, a través de la Policía Antinarcóticos y el Ejército Nacional, con el intromisivo apoyo de la DEA, ha adoptado diversas estrategias de erradicación y/o sustitución del arbusto de coca, la actividad cocalera no cesa. Sin los narcotraficantes, promotores comerciales del cultivo, tal actividad se circunscribiría a la magnitud que señalasen sus usos ancestrales. Son los narcotraficantes quienes captan la abrumadora mayoría de ganancias del negocio cocalero, promueven los cultivos en zonas donde ejércitos irregulares continúan imponiendo su ley, y donde la estrategia de trashumancia torna inoperantes los programas convencionales dejando atrás huellas de sangre y deforestación. 
Figura 11. Concentración espacial de las zonas con elevadas extensiones erradicadas y con grandes plantaciones de arbusto de coca entre las administraciones de Uribe II a Santos I

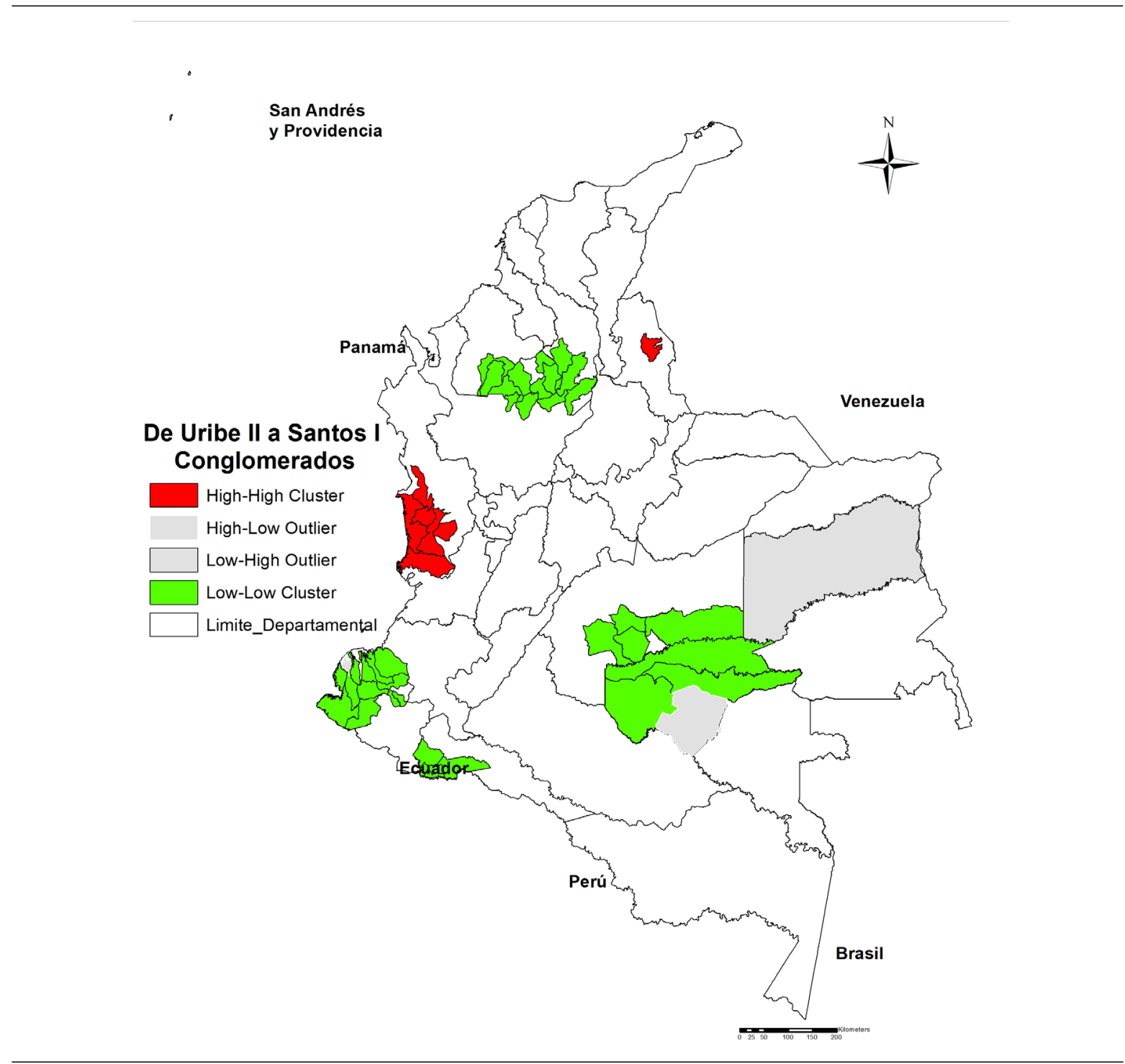

Fuente: elaborada con base en ODC (2018).

\section{Reflexiones finales}

Las áreas de actividad cocalera tienden a incrementarse ante las señales de un mercado del alcaloide en expansión. La cocaína que se presenta, además de en su forma tradicional como pasta básica, bajo la forma de clorhidrato, es ahora objeto de adulteración (Garat, 2018), con lo que se incrementan los riesgos para la salud pública derivados del consumo. La 2CB -tusibi en el lenguaje de los adolescentes- es una de las presentaciones que adopta la forma rosada o la amarilla de la cocaína, según los ingredientes con que se mezcle. No hay secreto tecnológico alguno para fabricarla y, además, sembrar el arbusto de coca en sus variedades más productivas es muy fácil. Por su parte, el 
Figura 12. Concentración espacial de las zonas con elevadas extensiones erradicadas y con grandes plantaciones de arbusto de coca entre las administraciones de Santos I a Santos II

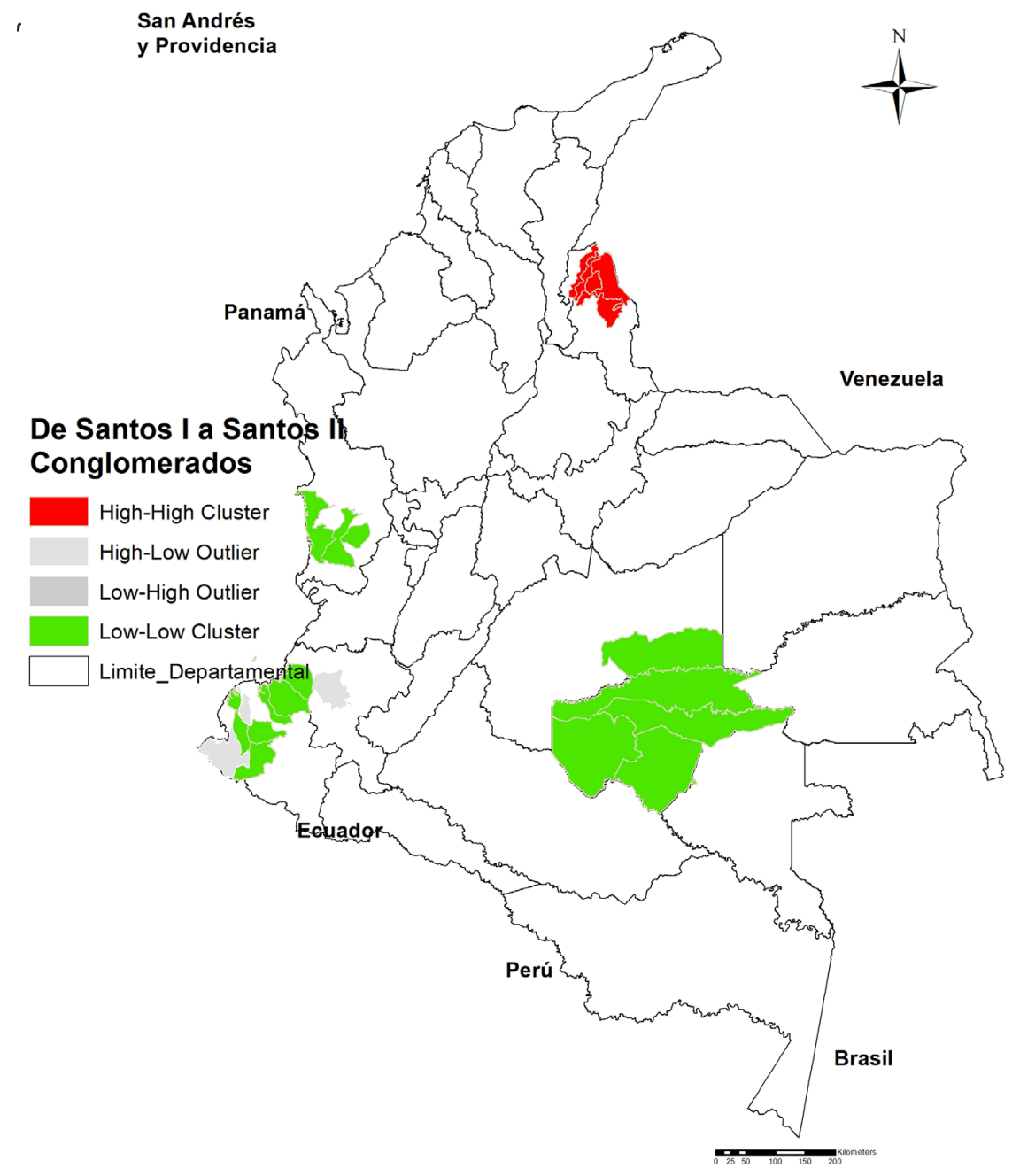

Fuente: elaborada con base en ODC (2018).

glifosato con el que se realiza la aspersión aérea es una sustancia con elevadas probabilidades de ser cancerígena y el Estado colombiano, como ocurrió recientemente con Monsanto, afronta el riesgo de ser condenado a pagar elevadas indemnizaciones a quienes contraigan cáncer por la aspersión aérea con el herbicida. En octubre de 2018, Reuters documentó que, después del fallo popular contra Monsanto, Bayer afronta otras 8.000 demandas. El juicio contra Monsanto, cuyo nombre planea eliminar Bayer por su mala reputación universal, se reabrirá ante las dudas argumentadas.

Son los campesinos empobrecidos a quienes se involucra en el conflicto y arriesgan la vida, al paso que los narcotraficantes, al amparo de su estrategia de trashumancia, disfrutan de las ganancias 
acumuladas en unos cuantos paraísos fiscales. Este panorama exige salidas ingeniosas y no meramente punitivas como la "erradicación forzada" que derivará en más derramamiento de sangre, incremento en la prevalencia de linfomas y un mayor deterioro ambiental. El principio de precaución debe prevalecer, y el trabajo académico debe contribuir a comprobar el daño grave e irreparable del glifosato. Además, debe argumentar posibles alternativas como la promoción de los usos industriales de la coca, ante el ensordecimiento universal existente frente las denuncias de los problemas que entraña la prohibición.

\section{Referencias bibliográficas}

Boyd, G. (2002). Collateral damage in the war on drugs. Villanova Law Review, 47(4), 1-13. Recuperado de https://www.aclu.org/files/FilesPDFs/collateral_damage.pdf

Caballero, A. (2018a). Sumisión. Semana. Recuperada de https://www.semana.com/opinion/ articulo/la-sumision-de-juan-manuel-santos-y-nestor-humberto-martinez-por-antoniocaballero/564452

Caballero, A. (2018b). Lo de Santrich y la DEA. Semana. Recuperada de https://www.semana.com/ opinion/articulo/sobre-la-captura-de-jesus-santrich-y-la-dea-por-antonio-caballero/563610

CAN -Comunidad Andina de Naciones-. (2013). Manual de Sustancias Químicas usadas en el procesamiento de drogas ilícitas. Proyecto PRADICAN. Recuperado de http://www.comunidadandina. org/StaticFiles/20135316739manual_sustancias_quimicas.pdf

Conklin, H. C. (1957). Hanunóo Agricultura: A report on an integral system of shifting cultivation in the Philippines. Roma, Italia: FAO.

Corbin, J. A. (s.f.). Los 5 tipos de cocaína (y diferencias en la adicción): una droga muy peligrosa que puede consumirse en distintos formatos. Recuperado de https://psicologiaymente.com/drogas/ tipos-de-cocaina

DANE -Departamento Administrativo Nacional de Estadistica-. (2018). Muestras censales 1964 2005 (Ipums) [Conjunto de datos]. Recuperado de https://www.dane.gov.co/index.php/ estadisticas-por-tema/demografia-y-poblacion/muestras-censales

DNP -Departamento de Planeación Nacional-. (2018). Normativa [Conjunto de datos]. Recuperado de https://www.dnp.gov.co/DNPN/normativa/leyes-plan-nacional-de-desarrollo

Dombois, R. (1989). Coca, derecho y violencia: Sobre la economía política de la coca en Colombia. Política y Sociedad, (2), 117-133. Recuperado de https://revistas.ucm.es/index.php/POSO/article/ view/POSO8989130117A/30674

Duncan, G. (2014). Más que plata o plomo. El poder político del narcotráfico en Colombia y México. Bogotá, Colombia: Penguin Random House Grupo Editorial.

Felbab-Brown, V. (2017). Lo que Colombia puede aprender de Tailandia sobre política de drogas. Revista De Economía Institucional, 19(37), 323-327. http://doi.org/10.18601/01245996.v19n37.15

FORENSIS -Instituto Nacional de Medicina Legal y Ciencias Forenses-. (2018). Boletines Estadísticos Mensuales -Instituto Nacional de Medicina Legal y Ciencias Forenses [Conjunto de datos]. Recuperado de http://www.medicinalegal.gov.co/cifras-estadisticas/boletines-estadisticos-mensuales 
Garat, G. (2018). Así se adulteran las drogas en América Latina. New York Times. Recuperada de https:// www.nytimes.com/es/2018/09/14/testeo-drogas-adulteradas-duque/?action=click\&clickSource=in icio\&contentPlacement=l\&module=toppers\&region=rank\&pgtype=Homepage

Garzón-Vergara, J. C. (2016). PosUNGASS 2016: América Latina y las perspectivas de la política de drogas. Consejo de Relaciones Internacionales de América Latina y el Caribe. Recuperado de http://cdn. ideaspaz.org/media/website/document/58110081f3d66.pdf

Gaviria, A. y Mejía, D. (Comps.). (2011). Políticas antidroga en Colombia: éxitos, fracasos y extravíos. Bogotá, Colombia: Ediciones Uniandes.

Guyton, K. Z., Loomis, D., Grosse, Y., El Ghissassi, F., Benbrahim-Tallaa, L., Guha, N. e IARC. (2015). Carcinogenicity of tetrachlorvinphos, parathion, malathion, diazinon, and glyphosate. Lancet Oncology, 16(5), 490-491. http://doi.org/10.1016/S1470-2045(15)70134-8

IDEAM -Instituto de Hidrología, Meteorología y Estudios Ambientales-. (2018). IDEAM [Conjunto de datos]. Recuperado de http://www.ideam.gov.co/

INS -Instituto Nacional de Salud-. (2015). Asunto: Apreciación reporte IARC clasificación herbicida glifosato. Recuperado de https://www.minsalud.gov.co/sites/rid/Lists/BibliotecaDigital/RIDE/IA/ INS/reporte-iarc-herbicida-glifosato.pdf

LSE -The London School of Economics and Political Science-. (2014). Ending the Drugs War: Report of LSE Expert Group on the Economics of Drug Policy. Recuperado de http://www.lse.ac.uk/ideas/ Assets/Documents/reports/LSE-IDEAS-Ending-the-Drug-Wars.pdf

Matteucci, S. y Morello, J. (s. f.). Aspectos ecológicos del cultivo de la coca. Mamacoca. Recuperado de http://www.mamacoca.org/docs_de_base/Cifras_cuadro_mamacoca/Coca.pdf

Mejía, D. y Rico, D. (2011). La microeconomía de la producción y el tráfico de cocaína en Colombia. En A. Gaviria y D. Mejía (Eds.), Políticas antidroga en Colombia: éxitos, fracasos y extravíos (pp. 15-40). Bogotá, Colombia: Ediciones Uniandes.

Monsanto. (2015). El informe de la IARC sobre el glifosato. Recuperado de http://www.monsantoglobal. com/global/ar/noticias-y-opiniones/pages/20150320.aspx

Nadelman, E. A. (1988). El costo social y financiero de la prohibición. Recuperado de http://bdigital. unal.edu.co/41050/1/12085-30578-1-PB.pdf

ODC -Observatorio de Drogas de Colombia-. (2017). Reporte de drogas de Colombia. Recuperado de http://www.odc.gov.co/Portals/1/publicaciones/pdf/odc-libro-blanco/reporte_drogas_ colombia_2017.pdf

ODC -Observatorio de Drogas de Colombia-. (2018). Oferta cultivos ilícitos [Conjunto de datos]. Recuperado de http://www.odc.gov.co/sidco/oferta/cultivos-ilicitos/departamento-municipio

RT - SEPA MÁS. (2015). Cómo las drogas envuelven el planeta. RT. Recuperado de https://actualidad. rt.com/actualidad/18221l-drogas-mapas-circular-planeta

Sorahan, T., Williams, G., Aardema, M. y Acquavella, J. (2016). A review of the carcinogenic potential of glyphosate by four independent expert panels and comparison to the IARC assessment. Critical Reviews in Toxicology, 46(S1), 3-20. http://doi.org/10.1080/10408444.2016.1214677 
Thoumi, F. E. (2014). Drogas ilegales y sus repercusiones en Colombia: el papel de las políticas y de los cambios institucionales. En Museo Nacional de Colombia (Ed.), Análisis histórico del narcotráfico en Colombia (pp. 281-303). Recuperado de http://www.museonacional.gov.co/ imagenes/publicaciones/analisis-historico-del-narcotrafico-en-colombia.pdf

Thoumi, F. (2016). Re-examining the "medical and scientific" basis for reinterpreting the Drug Treaties: Does the "regime" any clothes? Londres, Reino Unido: London School of Economics and Political Science.

Thoumi, F. E. (2017a). Medicina, ciencia e interpretación de las convenciones internacionales de drogas: ¿Será que el emperador está desnudo? Colombia Internacional, (89), 133-158.

Thoumi, F. E. (2017b). International Drug Conventions, Balanced Policy Recipes, and Latin American Cocaine Markets. En E. Savona, M. Kleiman y F. Calderoni (Eds.), Dual Markets - Comparative Approaches for Regulation (pp. 2-23). Ginebra, Suiza: Springer International Publishing AG.

UNGASS -Asamblea General de las Naciones Unidas-. (2016). Nuestro compromiso conjunto de abordar y contrarrestar eficazmente el problema mundial de las drogas. Nueva York, Estados Unidos: UNODC. Recuperado de https://www.unodc.org/documents/postungass2016/outcome/ V1603304-S.pdf

UNODC -Oficina de las Naciones Unidas contra la Droga y el Delito-. (2005). Producción y rendimiento de la hoja de coca en Colombia. Recuperado de http://www.biesimci.org/llicitos/produccion/Variedades. html

UNODC -Oficina de las Naciones Unidas contra la Droga y el Delito-. (2012). Métodos recomendados para la identificación y el análisis de materiales incautados (revisado y actualizado). Recuperado de https://www.unodc.org/documents/scientific/Cocaine_S.pdf

UNODC -Oficina de las Naciones Unidas contra la Droga y el Delito-. (2014). Informe mundial sobre las drogas, 2014. Recuperado de http://www.unodc.org/documents/wdr2014/WDR_2014_Spanish.pdf

UNODC -Oficina de las Naciones Unidas contra la Droga y el Delito-. (2016). Informe mundial sobre las drogas, 2014. Recuperado de https://www.unodc.org/doc/wdr2016/WDR_2016_ExSum_spanish. pdf

UNODC -Oficina de las Naciones Unidas contra la Droga y el Delito-. (2017a). Informe mundial sobre las drogas, 2017 - Fascículo 1. Recuperado de https://www.unodc.org/wdr2017/field/WDR_Booklet1_ Exsum_Spanish.pdf

UNODC -Oficina de las Naciones Unidas contra la Droga y el Delito-. (2017b). Informe mundial sobre las drogas, 2017 - Fascículo 2. Recuperado de https://www.unodc.org/wdr2017/field/Booklet_2_ HEALTH.pdf

UNODC -Oficina de las Naciones Unidas contra la Droga y el Delito-. (2017c). Informe mundial sobre las drogas, 2017 - Fascículo 4. Recuperado de https://www.unodc.org/wdr2017/field/Booklet_4_ ATSNPS.pdf

UNODC -Oficina de las Naciones Unidas contra la Droga y el Delito-. (2017d). Colombia, monitoreo de territorios afectados por cultivos ilícitos 2016. Recuperado de http://www.odc.gov.co/Portals/1/ publicaciones/pdf/oferta/censos/OF02012016_monitoreo_territorios_afectados_cultivos_ ilicitos_2016.pdf 
UNODC -Oficina de las Naciones Unidas contra la Droga y el Delito-. (2019). Colombia, Monitoreo de territorios afectados por cultivos ilícitos 2018. Recuperado de https://www.unodc.org/ documents/colombia/2019/Agosto/Informe_Monitoreo_de_Territorios_Afectados_por_Cultivos_ Ilicitos_2018.pdf

Urbina-Rangel, F. (2011). La coca. palabras-hoja para cuidar el mundo. Revista Maguaré, 25(2), 199-225.

Weinstock, J. A. (1983). Borneo - El rotén: un complemento de la agricultura migratoria. Recuperado de http://www.fao.org/docrep/q5240s/q5240s04.htm 